\title{
Violent Behaviour on Construction Sites: Structural Equation Modelling of its Impact on Unsafe Behaviour Using Partial Least Squares \\ DOI:
}

10.1108/ECAM-09-2019-0489

\section{Document Version}

Accepted author manuscript

Link to publication record in Manchester Research Explorer

Citation for published version (APA):

Adinyira, E., Manu, P., Agyekum, K., Mahamadu, A. M., \& Olomolaiye, P. (2020). Violent Behaviour on Construction Sites: Structural Equation Modelling of its Impact on Unsafe Behaviour Using Partial Least Squares. Engineering Construction and Architectural Management. https://doi.org/10.1108/ECAM-09-2019-0489

Published in:

Engineering Construction and Architectural Management

\section{Citing this paper}

Please note that where the full-text provided on Manchester Research Explorer is the Author Accepted Manuscript or Proof version this may differ from the final Published version. If citing, it is advised that you check and use the publisher's definitive version.

\section{General rights}

Copyright and moral rights for the publications made accessible in the Research Explorer are retained by the authors and/or other copyright owners and it is a condition of accessing publications that users recognise and abide by the legal requirements associated with these rights.

\section{Takedown policy}

If you believe that this document breaches copyright please refer to the University of Manchester's Takedown Procedures [http://man.ac.uk/04Y6Bo] or contact uml.scholarlycommunications@manchester.ac.uk providing relevant details, so we can investigate your claim.

\section{OPEN ACCESS}




\title{
Engineering Construction and Architectural Management
}

\section{DOI: 10.1108/ECAM-09-2019-0489}

\author{
Violent Behaviour on Construction Sites: Structural Equation Modelling of its \\ Impact on Unsafe Behaviour Using Partial Least Squares \\ ${ }^{1}$ Emmanuel Adinyira, ${ }^{2}$ Patrick Manu, ${ }^{3}$ Kofi Agyekum, ${ }^{4}$ Abdul-Majeed Mahamadu and \\ ${ }^{5}$ Paul Olomolaiye \\ ${ }^{1,3}$ Department of Construction Technology and Management, Kwame Nkrumah University of Science and \\ Technology, Kumasi Ghana \\ ${ }^{2}$ School of Mechanical, Aerospace and Civil Engineering, The University of Manchester, UK \\ ${ }^{4,5}$ Faculty of Environment and Technology, University of West of England Bristol, UK
}

Declaration of Interest statement: No Interest to Declare

Corresponding Author: Emmanuel Adinyira, eadinyira.cap@knust.edu.gh

\begin{abstract}
Purpose - Work on construction sites involve individuals with diverse character, temperament, age, physical strength, culture, religion, and experience level. A good number of these individuals are also alleged to involve themselves in substance and alcohol abuse due to the physically demanding nature of their work. These could promote the prevalence of violence on construction sites which could in turn affect safety on construction sites. However, there is a lack of empirical insight into the effect of violent behaviour and unsafe behaviour on construction sites. This study therefore pioneers an empirical inquiry into the relationship between violent behaviour and unsafe behaviour on construction sites.

Design/methodology/approach - Seventeen (17) violent behaviours and fifteen (15) unsafe behaviours were measured on 12 construction sites among 305 respondents using a structured questionnaire. A total of 207 valid questionnaire responses were collected from site workers. Partial Least Square-Structural Equation Modelling (PLS-SEM) technique was used to examine the relationship between violent behaviour and unsafe behaviour.
\end{abstract}


Findings - The results indicate that there is a significant positive relationship between violent behaviour and unsafe behaviour on construction sites.

Originality/value - The findings from this study provides valuable insight into a less investigated dimension of the problem of construction site safety management. A focus on attitudinal issues such as how workers relate toward others and towards self should be an important consideration in safety improvement interventions on construction sites.

Keywords - Construction site workers, Partial least squares, Structural equation modelling, Unsafe behaviour, Violent behaviour.

\section{INTRODUCTION}

The many problems associated with violence in the workplace have generated special interests among researchers for years now, and this has led to many scientific publications in the area within several sectors. Violence is a generic act covering all kinds of abuses (European Agency for Safety and Health at Work, EASHW, 2010). Violence has been defined in different ways by different researchers. In most of the definitions, some forms of violence at work such as homicide, assault, threats, mobbing, and the likes are highlighted (EASHW, 2010). Violence can be defined to include every behaviour that humiliates, degrades or damages one's well-being, value and dignity (EASHW, 2010). Violence is again described by the United State of America's Occupational Safety and Health Act of 1970 as any activity that could cause harassment, intimidation or physical violence or any other threatening and disruptive behaviour occurring at worksites. It could be in the form of threats, verbal abuse or even homicide.

Physical and psychological violence has gained much attention in both developing and developed countries (Di Martino et al., 2003). Violent acts at workplaces have negative effects on the productivity of an organisation as well as its workers. Winnet (2014) reported that workplace violence remains a major causal factor of death at the workplace. A report by the Health and Safety Executive (HSE) (2019) revealed that the estimated incidences associated with violence at work fluctuates on annual basis worldwide, without any precise trend. For instance, in a crime survey for England and Wales in 2017/2018, it was revealed that an estimated 1.5\% of working adults were victims of one or more violent incidents at work (HSE, 2019). The study further revealed the following facts: 374,000 adults of working age groups in employment experienced threats and assaults; an estimated 694,000 incidents of violence at workplace was recorded in 2017/2018 compared to the estimated 642,000 in 2016/2017.

In a working paper by Lippel (2016), it was revealed that, of the various working sectors where people were prone to violence, the health sector came up tops followed by the education sector, 
the domestic sector, the public sector, and the security sector in that order. In all these sectors, various forms of violence were reported to be prevalent. For instance, in the health sector, a study conducted by Lee et al. (2020) among Taiwanese emergency nurses concerning the prevalence of workplace violence revealed that about 378 emergency nurses experienced workplace violence of several forms over a period of 2 years. In another study conducted by Liu et al. (2019) to explore if Chinese nurse burnout and job satisfaction played mediating roles in the association of workplace violence and patients' safety, it was revealed that nurse-reported workplace violence was directly associated with higher incidences of burnout, less job satisfaction and lower patient safety. Considering another study by Li et al. (2019) among Chinese emergency nurses, it was reported that among 385 nurses surveyed, 89.9\% had experienced workplace violence in the previous year, with the violence having short- and long-term impacts on over $80 \%$ of them. Similar findings of workplace violence against health workers are reported in other countries (Yenealem et al., 2019; Schablon et al., 2018; Groenewold et al., 2018; Copeland and Henry, 2018; Boyle and McKenna, 2017; Schoenefisch and Pompeii, 2016). In the education sector, there have also been reported cases of workplace violence. A study by Tiesman et al. (2013) revealed that in Pennsylvania, special education teachers were highly prone to both physical and non-physical workplace violence. In another study by Williams et al. (2018) it was also revealed that in Virginia, special education teachers reported on being threatened and physically attacked than all other categories of teachers. In a review conducted by Reddy et al. (2018), it was revealed that workplace violence in the form of victimisation directed at educators appear across all levels of education and is present in almost every country as well. Violence within the domestic and security sectors are also well reported in literature (Ansorg and Gordon, 2019; Ahmad et al., 2016). Like other sectors, the construction sector is seen to be associated with violence which may appear in different forms.

The physically demanding nature of construction work and workplace stress associated with construction tend to increase the chances of the use and abuse of substance and alcohol. Workers on construction sites comprise of individuals with diverse character, temperament, age, physical strength, culture, religion and experience level. Construction workers could therefore react differently to circumstances, especially hazards that may come their way. According to Garber (2017), the Occupational Safety and Health Act assists contractors in regulating and mitigating jobsite hazards. However, outside the jobsite risks lies the less familiar but equally dangerous threat of workplace violence (Garber, 2017). As a high-pressure industry, there is the likelihood for confrontations to occur in the construction industry, and this can lead to verbal threats, shouting, cursing, fights, flared tempers and other violent acts (Kennedy, 2016). Despite these problems, it is surprising that the construction industry is not reported as one of the industry sectors most frequently affected by workplace violence. This notwithstanding, there are a good number of incidences which occur and go unreported (Kennedy, 2016). It is important to note that most of these violent acts if not checked may lead to unsafe behaviours which may eventually create 
serious issues on construction sites. Research to date has mainly focused on factors affecting unsafe behaviours in construction projects (Asilian-Mahabadi et al., 2018), analysis of complexities of unsafe behaviours in construction teams ( $\mathrm{Li}$ et al., 2018), and a review of factors influencing unsafe behaviours and accidents on construction sites (Khosravi et al., 2014). Only few of such studies have focused on aspects of violence associated with construction workforce. For instance, quite recently, Erdis et al. (2019) examined the causes, consequences and precautions of mobbing on construction professionals. However, to date there is no specific study in construction safety management that has tried to model the impact of violent behaviour on unsafe behaviour in the construction industry. Studies have shown that workers in different industrial contexts and different countries may vary in their perception and attitudes towards safety (AsilianMahabadi et al., 2018). Hence, it will be inappropriate to implement any proposed measures from such studies without making any adjustments to key variables reported in such studies. This study was therefore carried out to examine the relationship between violent behaviour and unsafe behaviour among workers on construction sites.

\section{LITERATURE REVIEW}

\section{Violent Behaviour}

Violence could be expressed in many forms ranging from physical assault to verbally abusing a person. NTWorkSafe (2015) explains the term 'violence at work' as the situation where in the discharge of one's duties, one is abused whether physically or verbally or is assaulted. The person involved could be an employee, client or any other person who may one way or the other be affected by the violent incidents at the workplace. The question of what constitutes violence is very complicated. It is very dependent on the culture of the person and the contextual complexities involved. It represents at a broad level the exhibition of aggressive behaviours.

Glomb et al. (2002), reports that, the first time a significant effort was made to come to a particular understanding on violence was in the year 1995 when the European Commission at an expert meeting defined it as 'incidents where persons are abused, threatened or assaulted in circumstances related to their work, involving an explicit or implicit challenge to their safety, well-being and health'. According to Chappell and Di Martino (2000) cited in Di Martino et al. (2003), the definition by the European Commission of experts centred on abuse, threat and assault. Abuse refers to the deviation from acceptable and reasonable conduct which could be in physical or psychological form. Threat on the other hand refers to the proclamation of an action intended to cause damage or harm. Assault also refers to any act that could cause one to suffer physical injury or harm. 
Aggressive behaviour is classified by Buss (1961) cited in Glomb et al. (2002), according to three facets: physical or verbal, active or passive, and direct or indirect. The physical or verbal facet is defined by whether aggression is exhibited through physical; for instance, hitting a co-worker, or verbal acts like threatening a co-worker. The active or passive facet is determined by whether harm is inflicted by engaging in some behaviours like yelling at a colleague or by withholding some actions like withholding much needed job information. The direct or indirect facet looks at whether harm is expressed directly at the target or through some intermediary.

Van Soest and Bryant (1995) developed a conceptual model describing three basic levels under which violence can occur to include; the individual level, structural level and institutional level. Out of these three levels, the most predominant in their opinion is the ones that occur at the individual level. There are also three basic types of violence as posited by Van Soest and Bryant (1995). They include acts of omission, alienation and repression. Violence can also be described based on where it originates. It could be from either the internal organisation or from outside the organisation in which case is described as external source. The internal source of violence arises from the management of the organisation and its employees. Some of such acts include bullying that takes place at various workplaces (Einarsen, 2000). Violent behaviour at workplaces can lead to negative outcomes for both individuals and organisations. Negative effects resulting from violence at workplaces include psychological and physiological effects such as stress disorders (Leymann and Gustafsson, 1996). Violence could also be in the form of psychological violence which may not be easily observed, but can be very devastating (Namie and Namie, 2000). Physical violence has long been recognised and given attention as compared to psychological violence.

Violent behaviour at workplace occur for several reasons. It could be a case of general violence inflicted by a disturbed person or someone on drugs or violence experienced by acts of intimidation in order to achieve a particular outcome or result. It could also be as a result of uncontrolled acts of irritation which may be in the form of extended acts of discomfort, anger or differences resulting from culture among workers and some other religious differences (NTWorkSafe, 2015). Discussed below are some of the violent behaviours that pertain to the construction industry and which have been reported in literature.

Verbal or written threats: Threats either in the form of verbal or written should be given the same attention at the workplace as physical violence. These threats are reported to be silent killers and should not be ignored (Lo et al., 2012; Health and Safety Authority, 2001). Evidence has emerged over the years concerning the harm caused by these forms of violence (NHS Health Scotland, 2010). It may normally begin as one unexpected or a series of repeated incidents. With time, it produces serious detrimental effects on the physical and mental wellbeing of its victims (NHS Health Scotland, 2010). 
Disturbing phone calls: Harassing or disturbing phone calls is one of the most stressful and frightening invasions of privacy anyone can experience (Privacy Rights Clearinghouse, 2016). This violent behaviour manifests itself when someone calls and uses threatening language, or even heavy breathing or silence to intimidate another person (Privacy Rights Clearinghouse, 2016). At the workplace, and especially, on construction sites, this gesture is also classified as a violent behaviour and it is well reported in literature (Lo et al., 2012; Hanley et al., 2008).

Sexual harassment: Sexual harassment can go either way, i.e., both men and women are prone to this kind of violent behaviour. It is a manifestation of power relations, but women are much more likely to be victims of sexual harassment than men. This is because more often women lack power, are in more vulnerable and insecure positions, lack self-confidence, or have been socialized to suffer in silence (Minnesota Advocates for Human Rights, 2003). On construction sites, sexual harassment against women is greatly reported (Lo et al., 2012; Hanley et al., 2008). Navarro-Astor et al. (2017) indicated that women who work in the construction industry have to put up with and endure this form of violent behaviour. Sexual harassment on the construction site against women comes in the form of obscene comments, wolf whistles, offensive languages, requests for sexual intimacies, fondling, among other things (Navarro-Astor et al., 2017).

Throwing objects or vandalizing to threaten staff: Throwing objects or vandalism to threaten the lives of staff are common violent behaviours exhibited by construction workers (Lo et al., 2012; Hanley et al., 2008; ILO, 2001). Vandalism involves broad category of crimes including the wilful behaviour that is aimed at destroying, altering, or defacing a property that belongs to another. Most of the times vandalism may be preceded by threats (ILO, 2001). The threats may have been explicit or veiled, spoken or unspoken, specific or vague, etc. At other times, the behaviour exhibited by some workers might suggest the potential for some violent act to occur. These notwithstanding, the onus lies with management to ensure that such violent behaviours and acts are prevented from happening (ILO, 2001).

Threatening by pointing of finger, verbal abuse, exclusion and isolation, slandering or maligning a worker and his/her family, deliberately withholding work-related information or supplying incorrect information of this kind, deliberately sabotaging or impeding the performance of work, obviously insulting, ostracising, boycotting or disregarding a person, shoving or pushing, hitting co-worker, unreasonable and/or unfounded refusal of request, shouting at staff to get things done, aggressively insisting that a way of doing things is always right, and repeated requests giving impossible deadlines or impossible tasks, are all typical violent behaviours that can be classified as part of bullying. The impact associated with the exhibition of these violent behaviours on construction sites are greatly reported in literature (Lo et al., 2012; Hanley et al., 2008; ILO, 2001; Health and Safety Authority, 2001; UNISON, 1996). Bullying was defined by Einarsen (1994, p. 20) as "emerging when one or several individuals persistently over a period of time perceive 
themselves to be on the receiving end of negative actions from one or several persons, in a situation where the one at the receiving end has difficulties in defending him/herself against these actions". Despite the known negative impact associated with bullying it is difficult dealing with this behaviour because the type of behaviour inflicted, be it verbal or non-verbal is often carried out within the operational rules and regulations of the particular organization (Snook, 2015). It becomes severe when it is ingrained into the organization's culture to the extent that management of the organization sees nothing wrong with it. This notwithstanding, bullying acts as a poison which seeps into the psychological well-being of the victim, as well as damaging the organization's reputation and negatively impacting the productivity of surrounding workers (Snook, 2015).

Table 1 summarizes some of the workplace violent behaviours identified from literature.

Table 1 Workplace violent behaviours identified from literature

\begin{tabular}{|c|c|c|}
\hline Code & Violent behaviour & $\begin{array}{l}\text { Studies from which violent } \\
\text { behaviours were extracted }\end{array}$ \\
\hline$\overline{\mathrm{VS} 1}$ & Verbal or written threats & $\begin{array}{l}\text { NHS Health Scotland, 2017; } \\
\text { Lo et al., 2012; Health and } \\
\text { Safety Authority, 2001 }\end{array}$ \\
\hline VS 2 & Disturbing phone calls & $\begin{array}{l}\text { Privacy Rights } \\
\text { Clearinghouse, 2016; Lo et } \\
\text { al., 2012; Hanley et al., } 2008\end{array}$ \\
\hline VS 3 & Sexual harassment & $\begin{array}{l}\text { Navarro-Astor et al., 2017; } \\
\text { Lo et al., 2012; Hanley et al., } \\
\text { 2008; Minnesota Advocates } \\
\text { for Human Rights, } 2003\end{array}$ \\
\hline VS 4 & Throwing objects or vandalizing to threaten staff & $\begin{array}{l}\text { Lo et al., 2012; Hanley et al., } \\
\text { 2008; ILO, 2001 }\end{array}$ \\
\hline VS 5 & Threatening by pointing of finger & Lo et al., 2012; ILO, 2001 \\
\hline VS 6 & Verbal abuse & $\begin{array}{l}\text { Lo et al., 2012; Hanley et al., } \\
\text { 2008; Health and Safety } \\
\text { Authority, 2001; UNISON, } \\
1996\end{array}$ \\
\hline VS 7 & Exclusion and isolation & $\begin{array}{l}\text { Snook, 2015; Lo et al., 2012; } \\
\text { Hanley et al., 2008; Health } \\
\text { and Safety Authority, 2001; } \\
\text { UNISON, } 1996\end{array}$ \\
\hline VS 8 & Slandering or maligning a worker and his/her family & $\begin{array}{l}\text { Snook, 2015; Hanley et al., } \\
\text { 2008; Health and Safety } \\
\text { Authority, 2001; ILO, } 2001\end{array}$ \\
\hline
\end{tabular}




\begin{tabular}{|c|c|c|}
\hline VS 9 & $\begin{array}{l}\text { Deliberately withholding work-related information or } \\
\text { supplying incorrect information of this kind }\end{array}$ & $\begin{array}{l}\text { Snook, 2015; Hanley et al., } \\
\text { 2008; UNISON, } 1996\end{array}$ \\
\hline VS 10 & $\begin{array}{l}\text { Deliberately sabotaging or impeding the performance } \\
\text { of work }\end{array}$ & $\begin{array}{l}\text { Snook, 2015; Health and } \\
\text { Safety Authority, 2001; ILO, } \\
2001\end{array}$ \\
\hline VS 11 & $\begin{array}{l}\text { Obviously insulting, ostracising, boycotting or } \\
\text { disregarding a person }\end{array}$ & $\begin{array}{l}\text { Snook, 2015; ILO, 2001; } \\
\text { Health and Safety Authority }\end{array}$ \\
\hline VS 12 & Shoving or pushing & $\begin{array}{l}\text { Snook, 2015; Lo et al., 2012; } \\
\text { ILO, } 2001\end{array}$ \\
\hline VS 13 & Hitting co-worker & Snook, 2015; Lo et al., 2012 \\
\hline VS 14 & Unreasonable and/or unfounded refusal of request & Snook, 2015; ILO, 2001 \\
\hline VS 15 & Shouting at staff to get things done & $\begin{array}{l}\text { Snook, 2015; Health and } \\
\text { Safety Authority, } 2001\end{array}$ \\
\hline VS 16 & $\begin{array}{l}\text { Aggressively insisting that a way of doing things is } \\
\text { always right }\end{array}$ & $\begin{array}{l}\text { Health and Safety Authority, } \\
\text { 2001; ILO, 2001; UNISON, } \\
1996\end{array}$ \\
\hline VS 17 & $\begin{array}{l}\text { Repeated requests giving impossible deadlines or } \\
\text { impossible tasks }\end{array}$ & $\begin{array}{l}\text { Health and Safety Authority, } \\
\text { 2001; UNISON, } 1996\end{array}$ \\
\hline
\end{tabular}

\section{Unsafe behaviour in the construction industry}

Despite the safety awareness created by researchers and practitioners in the construction industry, accident rate within the industry remains very high. Studies conducted to ascertain the reasons for this high accident rate have shown that human error plays a key role (Liao et al., 2016). According to Lehtola et al. (2008), even though strict regulations can be imposed on the way workers behave at the workplace, they can still be compelled to perform their duties unsafely because of the restrictions of their workmanship and the working environment. Studies have shown that most of the accidents and injuries that emanate from the workplace can be attributed to unsafe worker behaviours, a reflection of system deficiency and hazardous work environments (Dodoo and AlSamarraie, 2019; Liao et al., 2017; Fang et al., 2016; Liu et al., 2015; Khosravi et al., 2014).

Various descriptions for unsafe behaviour have evolved over the years. Reason et al. (1990) describes unsafe behaviour to mean an intentional violation of standard procedures that may lead to errors. This description was improved upon by Mason (1997) who described unsafe behaviour as an individual's possibility of not following standard safety rules, procedures, instructions and specified criteria for obligatory work. Fam et al. (2012), agreed with the description of Mason (1997) and further described unsafe behaviour as any behaviour involved in by an employee without considering safety rules, standards, procedures, instructions, and specified criteria in the 
system that can undesirably influence the system safety or compromise the safety of the employee or their colleagues. Following this description by Fam et al. (2012), Mohammadfam et al. (2017) reiterated that unsafe behaviour has a prominent place in occupational accidents, an issue that has been stressed by several studies worldwide. As far back as 1959, studies showed that, about $85 \%$ of all accidents worldwide were attributed to unsafe acts that result from unsafe behaviour (Mohammadfam et al., 2017).

A study conducted by Abdelhamid and Everett (2000) revealed unsafe behaviour to be a key cause of accidents in the construction industry. In a further study, Fleming and Ladner (2002) indicated that such behaviour result in $80-90 \%$ of the accidents on construction sites. These unsafe behaviours are normally exhibited by workers or work teams in the construction industry (Haslam et al., 2005). Even though unsafe behaviour by itself is regarded as the main cause of accidents in many industries, there are several factors which can have direct or indirect influence on the behaviour of individuals within such organizations, hence, indirect effect on accidents. The influence of unsafe behaviour on accidents in the construction industry is well reported in literature (Hinze et al., 2013; Payne et al., 2009; Sa et al., 2009; Lipscomb et al., 2008; Grabowski et al., 2007; Haslam et al., 2005; Suraji et al., 2001). Since unsafe behaviour has attracted attention in recent years and companies have increasingly been using it to measure their safety performances, behaviour-based safety management (BBS) has been introduced (Mohammadfam et al., 2017). The essence of the BBS is to improve overall safety performances of organizations by improving the safety behaviour of employees in those organizations (Mohammadfam et al., 2017; Choudhry, 2014). Among the unsafe behaviours exhibited in the construction industry are the following:

Failure to warn or secure members out of danger: This unsafe behaviour is highly reported in literature (Grytnes et al., 2020; Huang and Yang, 2019; Shamsuddin et al., 2015). On construction sites, accidents can easily occur if supervisors fail or ignore to warn other members who work on high risk tasks. Huang and Yang (2019) indicated that when employers fail to provide the needed assistance to employees with regards to safety practices related to specific tasks, employees are exposed to high risks. In the view of Grytnes et al. (2020), before any construction worker sets foot on the site, he or she must be aware of possible hazards associated with the works they will be doing. It is therefore the work of the construction manager to ensure that such individuals are aware of the dangers associated with their tasks (Huang and Yang, 2019). Any manager that fails to warn their subordinates about potential risks and advises them on how to ensure their safety has failed as a proper manager (Hojati, 2018).

Working at improper speeds: This unsafe behaviour has also been widely spoken about in literature (Nawaz et al., 2020; Adebayo and Emoh, 2019; Nadhim, 2019). When workers are forced to work at improper speeds they can be confused, which will in turn lead to a lack of mindfulness that has the potential to harm them as well as their co-workers (Nadhim, 2019). Unless otherwise necessary, it is important for workers to be extra vigilant at what is in their surrounding before deciding to work at unnecessary speeds. 
Improper lifting, handling and moving objects: Studies have shown that improper lifting, handling and moving of objects was reported to be one of the most common causes of accidents from 2006 to 2017 ( $\mathrm{Li}$ et al., 2019). It is an unsafe behaviour widely reported in literature (Guo et al., 2020; Li et al., 2019; Xu et al., 2019). Improper lifting, handling and moving of objects usually result from manual works which are carried out on construction sites (Li et al., 2019; Xu et al., 2019). According to Askorn and Hadikusumo (2007), most workers on construction sites prefer to carry heavy objects without using any lifting devices. This may be due to the fact that they may be unaware of the safe method for carrying out such particular tasks. Such manners and conditions could create serious musculoskeletal injuries to the workers (Li et al., 2019). In the study of Askorn and Hadikusumo (2007), it was revealed that most construction workers manually lifted, handled or moved materials on site because such practices have been practiced for a long time and has become the norm.

Improper placing and stacking of objects and materials in dangerous locations: Problems associated with improperly placing and stacking objects in dangerous locations are widely reported in literature (Liang et al., 2019; Nadhim, 2019; Lawton, 2014, Askorn and Hadikusumo, 2007). Improper stacking and storage of objects and materials can result in serious injuries to workers and damages to costly materials (Lawton, 2014). In the view of Askorn and Hadikusumo (2007), when objects are improperly placed and stacked in dangerous locations, a worker could collide with it, the result of which is an unpredicted accident. If a worker bumps into improperly stacked objects and materials on site, there is the likelihood for him or her to topple over and hurt themselves. Nadhim (2019) indicated that there is also that temptation for employees to poorly retrieve materials which are improperly stacked, and this has the tendency to lead to sprain or other injuries.

Incorrect use of tools and equipment and using defective equipment and tools to work: Using tools properly on construction sites is only one facet of job site safety, which is also extremely important. This unsafe behaviour is well reported in literature (Huang and Yang, 2019; Cermelli et al., 2019; Berhanu et al., 2019; Askorn and Hadikusumo, 2007). In a study by Berhanu et al. (2019), it was revealed that construction workers who used vibrating hand tools were more likely to be injured compared with their colleagues who use other types. Such accidents are mostly due to the incorrect use of such tools or probably because such tools were defective. Askorn and Hadikusumo (2007) also reported that construction workers who usually climb or stand on rebars instead of using ladders were at higher risks of falling and injuring themselves. On the other hand, if a worker uses a substandard ladder, there is the tendency for that worker to fall and injure himself/herself as well. This enforces the fact that in addition to using the correct tool, that tool should not be defective.

Annoyance and horseplay in the workplace: Horseplay is a rough or boisterous play or pranks that occur at the workplace (Environmental Health and Safety Office, EHSO, 2017). It includes activities like joking, playing around, racing, grabbing, foolish vehicle operation, social pressure to partake in unsafe acts, harassment and unauthorized contests, among other things (EHSO, 2017). As a high-risk sector such acts should not be condoned in the construction industry (Lingard et al., 
2019). According to Askorn and Hadikusumo (2007), annoyance and horseplay in the industry, especially, where workers roughly play around can lead to unexpected accidents.

Ignoring to wear personal protective equipment: This is one of the most widely reported unsafe behaviours in the construction industry (Guo et al., 2020; Huang and Yang, 2019; Burton, 2017; Askorn and Hadikusumo, 2007). There are many workers who appreciate the wearing of personal protective equipment. However, for every willing employee, there are stubborn ones who do not care gambling with their safety (Burton, 2017). According to Askorn and Hadikusumo (2007), when workers refuse to wear PPEs, their chances of getting injured are increased.

Removing safety guards from the workplace or equipment: When safety guards are removed from equipment or the workplace, there is an increase in the potential for accidents to occur (Aksorn and Hadikusumo, 2007). Most equipment guards carry distinct signs in the form of the knowledge that a worker's life is needlessly taken or will be irreversibly changed by the absence of a simple lock or a piece of metal or plastic. Aside death, amputation is one of the most severe types of injuries a person can sustain where safety guards are removed either intentionally or accidentally from equipment on the construction site. According to Aksorn and Hadikusumo (2007), steel workers are more susceptible to injuries that result from the removal of safety guards from equipment.

Leaving nails or other sharp objects protruding from timber: This unsafe behaviour is reported to be a significant cause of accidents on construction sites (Mustapha et al., 2015; Aksorn and Hadikusumo, 2007). Exposed rebar ends and nails from timber pose serious risks to construction workers (Aksorn and Hadikusumo, 2007). When such objects are left in timber, they can stick out and pose hazards to workers who may cut or scratch themselves on the sharp ends. Workers that stumble or fall onto such exposed objects can be pierced or impaled causing serious internal injuries and at times death.

Throwing or accidentally dropping objects from high levels: This unsafe behaviour is well reported in literature (Nadhim et al., 2016; Aksorn and Hadikusumo, 2007). Accidentally dropping objects whiles working on site can cause serious head injuries to people when they are struck by such objects. Among the most common injuries suffered by workers as a result of this unsafe behaviour are bruises, fractures, strains and sprains. On typical construction sites the objects that accidentally fall are roof trusses and steel beams, and among those that are thrown about are fasteners and small hand tools.

Working under the effects of alcohol and other drugs: Under this condition the unawareness level of workers is increased, and hence, the occurrence of accidents. Literature reports on this unsafe behaviour as a contributory factor to accidents on site (Oswald et al., 2015; Marques et al., 2014).

Improper positioning of and posture for tasks: Improper positioning of tasks has the tendency to cause workers to fall, especially, from heights. Also, improper posture for tasks, which is highly evident when workers take short cuts by climbing or jumping from high levels instead of using 
ladders could result in serious injuries (Liang et al., 2019; Lop et al., 2019; Aksorn and Hadikusumo, 2007).

Working with lack of concentration: Lack of concentration whiles working can lead to the occurrence of accidents on site (Bhole, 2016; Aksorn and Hadikusumo, 2007). This unsafe behaviour is evident where workers talk whiles undertaking series of jobs and activities on the site (Bhole, 2016; Aksorn and Hadikusumo, 2007). Table 2 provides a summary of the preceding unsafe behaviours and the studies from which they were extracted.

Table 2. List of unsafe behaviours assessed

\begin{tabular}{|c|c|c|}
\hline Code & Unsafe behaviours & $\begin{array}{l}\text { Studies from which unsafe } \\
\text { behaviours were extracted }\end{array}$ \\
\hline UB1 & $\begin{array}{l}\text { Failure to warn or to secure members out of } \\
\text { danger }\end{array}$ & $\begin{array}{l}\text { Grytnes et al., 2019; Huang and Yang, } \\
\text { 2019; Hojati, 2018; Shamsuddin et } \\
\text { al., } 2015\end{array}$ \\
\hline UB2 & Working at improper speeds & $\begin{array}{l}\text { Nawaz et al., 2020; Adebayo and } \\
\text { Emoh, 2019; Nadhim, } 2019\end{array}$ \\
\hline UB3 & Improper lifting, handling or moving of objects & $\begin{array}{l}\text { Guo et al., 2020; Li et al., 2019; Fu et } \\
\text { al., 2019; Askorn and Hadikusumo, } \\
2007\end{array}$ \\
\hline UB4 & $\begin{array}{l}\text { Improper placing and stacking of objects and } \\
\text { materials in dangerous locations }\end{array}$ & $\begin{array}{l}\text { Liang et al., 2019; Nalim, 2019; } \\
\text { Lawton, 2014; Askorn and } \\
\text { Hadikusumo, } 2007\end{array}$ \\
\hline UB5 & $\begin{array}{l}\text { Incorrect use of tools and equipment, hand } \\
\text { tools etc. }\end{array}$ & $\begin{array}{l}\text { Huang et al., 2019; Cermelli et al., } \\
\text { 2019; Berhanu et al., 2019; Askorn } \\
\text { and Hadikusumo, } 2007\end{array}$ \\
\hline UB6 & Using defective equipment and tools to work & $\begin{array}{l}\text { Cermelli et al., 2019; Askorn and } \\
\text { Hadikusumo, } 2007\end{array}$ \\
\hline UB7 & Annoyance and horseplay in the workplace & $\begin{array}{l}\text { Lingard et al., 2019; Environmental } \\
\text { Health and Safety Office, } 2017 ; \\
\text { Askorn and Hadikusumo, } 2007\end{array}$ \\
\hline UB8 & $\begin{array}{l}\text { Ignoring to wear personal protective equipment } \\
\text { (PPE) }\end{array}$ & $\begin{array}{l}\text { Guo et al., 2020; Huang and Yang, } \\
\text { 2019; Burton, 2017; Askorn and } \\
\text { Hadikusumo, 2007 }\end{array}$ \\
\hline UB9 & $\begin{array}{l}\text { Removing safety guards from the workplace or } \\
\text { equipment }\end{array}$ & Aksorn and Hadikusumo,2007 \\
\hline
\end{tabular}




\begin{tabular}{lll}
\hline \hline UB10 & $\begin{array}{l}\text { Leaving nails or other sharp objects protruding } \\
\text { from timber }\end{array}$ & $\begin{array}{l}\text { Mustapha et al., 2015; Aksorn and } \\
\text { Hadikusumo,2007 }\end{array}$ \\
\hline UB11 & $\begin{array}{l}\text { Throwing or accidentally dropping objects } \\
\text { from high levels }\end{array}$ & $\begin{array}{l}\text { Nadhim et al., 2016; Aksorn and } \\
\text { Hadikusumo,2007 }\end{array}$ \\
\hline UB12 & Working under the effects of alcohol and other & $\begin{array}{l}\text { Oswald et al., 2015; Marques et al., } \\
\text { 2014 }\end{array}$ \\
& drugs & $\begin{array}{l}\text { Liang et al., 2019; Lop et al., 2019; } \\
\text { Aksorn and Hadikusumo, 2007 }\end{array}$ \\
\hline UB13 & Improper positioning of tasks & $\begin{array}{l}\text { Liang et al., 2019; Lop et al., 2019; } \\
\text { Aksorn and Hadikusumo, 2007 }\end{array}$ \\
\hline UB14 & Improper posture for tasks & $\begin{array}{l}\text { Bhole et al., 2016; Aksorn and } \\
\text { Hadikusumo,2007 }\end{array}$ \\
\hline UB15 & Working with lack of concentration & . \\
& &
\end{tabular}

\section{Antecedents of Unsafe worker behaviour in the construction industry}

A worker's unsafe behaviour results from a cognitive failure (Jiang et al., 2014). The critical factors that can result in a worker's cognitive failure can be categorised into five cognitive stages to include: detecting hazards; recognizing hazards; perceiving responses; selecting a safe response; and executing a safe response (Jiang et al., 2014).

An extensive review of literature conducted by Zerguine et al. (2016) revealed several antecedents of unsafe behaviours of workers. These antecedents were categorised into: project management (commitment and support, management style and competency); society (education and training, social support and economy); workgroup (interaction); organisation (policy and plan, climate and culture, structure and responsibility, information management, project and job design); site condition (hazardous operations, unsafe condition, welfare service); supervision (effective enforcement, safety engagement, communication, performance pressure); individual factors (attitude and perception, age and experience, intended acts, competency and ability, psychological features); and contractor (size, interaction, incentives, competency). Other studies have identified other antecedents of unsafe behaviour in the construction industry to include lack of adequate knowledge on safety and non-compliance with established work procedures (Nyende-Byakika, 2016; Dong et al., 2015; Choudhry and Fang, 2008). In other similar studies, organisational factors (e.g. poor and unsafe work environment and pressure to meet deadlines) were identified as antecedents to unsafe behaviours in the construction industry (Ghasemi et al., 2018; Han et al., 2014). Psychological issues like stress and pressure have also be found to be key antecedents of unsafe worker behaviour in the construction industry (Choudhry and Fang, 2008). 
To achieve the International Labour Organization's aim of zero harm in the workplace, Dodoo and Al-Samarraie (2019) recommended that the solutions to unsafe behaviours at the construction site should be of both an employee and organizational type. Liao et al. (2017) recommended to management in the construction industry to enhance its image as role models in terms of safety. This according to Liao et al. (2017) can be achieved by increasing workers' awareness of risks associated with unsafe behaviours. Workers within the construction setting should therefore be encouraged to put up safe behaviours. Despite the many antecedents of unsafe behaviour reported in literature, the role of violence as a potential antecedent is yet to be empirically verified in the construction industry.

\section{Theories of violent and unsafe behaviours}

\section{Commonly used theory of unsafe behaviour in construction related research}

As one of the most important industries worldwide that provides up to $10 \%$ employment and economic growth, the construction industry has also been tagged as one of the most hazardous industries (Xu et al., 2018). Accidents and their related deaths and injuries are a major issue on construction sites (Ghasemi et al., 2018). In most developing countries, the construction industry has been identified as a higher risk sector compared to manufacturing industries (AsilianMahabadi et al., 2018). Within this industry, accidents cause fatalities, injuries, financial losses, and schedule overruns (Xu et al., 2018). It is widely held that, lessening unsafe acts on site can improve safety performance on construction projects. Though substantial research efforts have been undertaken to eliminate unsafe acts, accidents still prevail because of the unsafe behaviours exhibited by workers within the industry (Xu et al., 2018; Asilian-Mahabadi et al., 2018). The Theory of Planned Behaviour (TPB) has been identified as the prevailing theoretical framework of unsafe acts (Xu et al., 2018; Ajzen, 1991). This theory has greatly been used to analyse unsafe acts in the construction industry (Xu et al., 2018).

When Ajzen (1991) developed the theory of planned behaviour, factors of human behaviour (i.e. attitude, subjective norm and perceived behavioural control) were identified. Xu (2018, p. 2), defined these three human behaviours to mean the following: "Attitude is the value attributed to the performance of the behaviour, an indication that the most favourable behaviour will more likely occur; the subjective norm refers to the social pressure to carry out a certain behaviour (i.e the behaviour under greater pressure is most likely to happen); and the perceived behavioural control is the prejudgment of the possibility to perform certain behaviour, with the easiest behaviour most likely to happen". To assist in promoting safe behaviour on construction sites, various studies have been conducted based on the TPB. For instance, Cavazza and Serpe (2009) dwelt on the TPB and postulated that improving safety performance was as a result of psychological changes and positive attitudes after safety training programmes. Goh and Binte Sa'adon (2015) also utilized the TPB to examine the key variable of the cognitive decision-making process of unsafe behaviours of scaffolders. Quite recently, Fang et al. (2016) also utilized the TPB and came out with a 
framework which spells out the social psychological causes of unsafe behaviour, and further used it to establish the relationship between safety attitude and unsafe behaviour. Since the TPB was an open theoretical framework, it meant that new factors could be added to improve on the explanation of the human behaviour. As a matter of fact, researchers who used the TPB in their studies aimed at expanding it with additional factors to help better explain the human behaviour (Xu et al., 2018). For instance, the Theory was adopted and modified and other factors such as past behaviour and habits, belief salience, morality and self and group identities added in the works of Conner and Armitage (2009) and Moan and Rise (2006). Recently, Xu et al. (2018) expanded the TPB model to examine whether attitudinal ambivalence was a mediating factor, either fully or partially, in the relationship between safety attitude and safety behaviour.

\section{Theories of violence}

Unlike unsafe behaviours, there is currently no known theory of violence used in the construction industry. Despite the known issues of violence associated with the construction industry, it is surprising that the industry is not reported as one of the industrial sectors most frequently affected by workplace violence. As a matter of fact, there are a good number of incidences and workplace violence which occur and go unreported (Kennedy, 2016). Among the known theories of violence generally reported in literature are the Bandura Theory, The Baerends Theory, The Berkowitz Theory, The Subculture of Violence Theory and the Regional Culture of Violence Theory (Olson, 1994).

The Bandura Theory was proposed in 1973 and it states that, aggressive behaviours are learned through observation of familial, subcultural and media events that are imitated. These behaviours are commonly expressed in situations where positive outcomes are expected, aversive treatments are extinguished, and where instructional control is present (Olson, 1994). Following this theory, Berkowitz (1974) studied the factors that increase the aggression to an act of violence and found that the inadequate consequences that follows the previous act served as a basic disinhibiting influence. Berkowitz (1974) further indicated that the altered cognitive functioning during adolescence leads to the classic frustration-aggression dynamic, and this causes a nonpremeditated violent act arising out of the culprit's unfulfilled expectations. The Baerends Theory was further initiated in 1979 and was based on data retrieved from animals and which supports the notion of human territorial issues and socio-political economics as the major determinants of aggression. For this theory, the violent behaviour should not only be interpreted for its harmful intent, but for the common aim of escape interaction, social, sexual or parental control (Olson, 1994). Before these Theories were proposed, Wolfgang and Ferracuti (1967) had already proposed the Subculture and Regional Culture of Violence Theory. This theory provided an explanation to the sociodemographic patterning of violence (Olson, 1994). The main premise of this theory is that certain groups embrace the use of violence as a means of conflict resolution (Olson, 1994). The Regional culture of violence also postulated that geographical norms influence the use of violence in general (Messner, 1988). 
Despite these known theories, Olson (1994, p. 479) indicated that because occupational safety and health has focused on "more obvious, tangible workplace hazards, the problem of violence has gone unaddressed". This is the issue that was reiterated by Kennedy (2016). Currently, there is no specific regulation that prevent worker fatalities due to violence, however, the general duty clause contained in the Occupational Health and Safety Act of UK charges employers with this responsibility. Violence has now become an important worksite hazard in all sectors of the economy (HSE, 2019; Winnet, 2014). Violent behaviour is a subcategory of aggressive behaviour (Seddig and Davidov, 2018). Aggression is a behaviour that is exhibited with the intention of causing immediate harm to another person (Seddig and Davidov, 2018). Aggression can appear in one or two forms, i.e. direct (e.g. threatening, mocking, name-calling) and indirect (e.g. gossiping, manipulation of victim's social status and relationships) (Seddig and Davidov, 2018). The relationship between violent behaviours and unsafe behaviours in the workplace is further explained in the sub-section that follows.

\section{Relationship Between Violent Behaviour and Unsafe Behaviour}

Workplace violence as conceptualized in this paper focuses more on interpersonal forms of violence rather than organizational workplace deviance. The focus is on violence from persons working within the organisation rather than from persons outside the organizations. The construct of violence is defined beyond behaviours to include the intention to harm considered on all dimensions i.e. physical or verbal, active or passive, and direct or indirect. Construction workers by the very nature of their work are exposed to high job-related stress. Cullinan et al. (2019) indicated that work related stress has become prevalent in all sectors, and has important consequences for employees, employers, the economy, and the society. In their study, Cullinan et al. (2019) examined the relationship between bullying (a form of violence) and subjective workrelated stress and revealed that employees who were bullied often experienced work-related stresses. Other researchers have suggested associations between job stressors and the emotional reactions of anger (Sohn et al., 2018; Aytac, 2015), feelings of hostility (Meisler et al., 2019; Mosadeghrad et al., 2014), and a self-reported assessment of the trait of aggression (Malik et al., 2018). Aside the organizational environment, there are also individual antecedents of engaging in violent behaviour. This is not only consistent with several theories of aggression (e.g., Neuman and Baron, 1997; Berkowitz, 1994), but is also supported by considerable research. Individual traits such as past aggressive behaviour, trait anger, impulsiveness, and substance abuse have been reported in literature as significant predictors of violent behaviour (Estévez et al., 2018; Hsieh and Chen, 2017).

Very little empirical research is however reported in literature on the consequence of workplace violence. This may be because workplace violence is often the outcome of interest (Nieto- 
Gutierrez et al., 2018). Several of the existing theoretical models only focus on workplace aggression or violence without looking at the potential repercussions of being the target of and engaging in violent conduct on the workplace (Nieto-Gutierrez et al., 2018). Although there is evidence of positive consequences of aggressive acts, most research suggests primarily negative consequences of experiencing aggressive behaviours. The negative outcomes can occur for both the targets and the perpetrators of violent acts. Examples of such negative outcomes include job dissatisfaction, job stress, headaches, sleep problems, absence, turnover intentions, reciprocal aggression, and worsened working relations (Estévez et al., 2018). Other studies such as Bilsky and Hermann (2016), Benish-Wiesman (2015) and Benish-Weisman and McDonald (2015) have reported on violence in other sectors. In the construction industry, there have been series of studies that looks at unsafe behaviours (see Table 2). Other studies have also considered violent behaviours that occur in the construction industry (see Table 1). However, very little is known about the impact of violent behaviour on construction sites on unsafe behaviour. This therefore becomes an enormous and a necessary gap which this study seeks to bridge. Based on the studies reported in Tables 1 and 2 and the theoretical considerations, this study investigates if violent behaviours have any effect on safety behaviour (unsafe behaviour). The guiding research hypothesis is that "violent behaviour on construction sites has a positive correlation with unsafe behaviour of construction workers' and this is graphically shown in Figure 1.

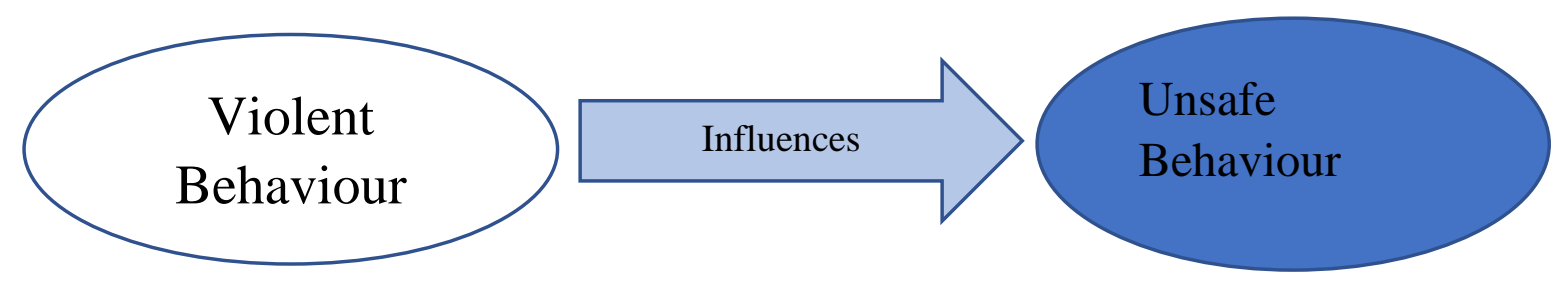

Figure 1: Conceptual model to examine the relationship between violent behaviour and unsafe behaviour 


\section{METHODOLOGY}

\section{Questionnaire Survey}

This study adopted a quantitative survey research design using a questionnaire as the data collection instrument primarily because of the need to collect large amount of data to statistically test the study's hypothesis. A structured questionnaire was developed and administered to workers on construction sites. The structured questionnaire was designed to constitute three sub-sections. The first sub-section of the questionnaire described the socio-demographic characteristics of the surveyed respondents. The key socio-demographic characteristics of the respondents that were collected included age, gender, level of education, working experience in the construction industry and role on site. The second sub-section of the questionnaire sought the perception of respondents on the level of violent behaviour on their site using a five-point Likert type of closed-ended questions. Respondents were asked to rate identified violent behaviour according to their degree of occurrence on their sites on a five-point Likert scale (1 - never, 2 - rarely, 3 - sometimes, 4 often, 5 - always). The same was adopted in the third sub-section of the questionnaire to determine the unsafe behaviours observed on the site.

To guarantee validity and reliability of the questionnaire, a pre-test was done with 10 respondents. The administration of the questionnaire with the 10 respondents was completed in a week. The data was examined for internal consistency of the questionnaire. A limited number of wording changes were made to some of the statements and questions of the questionnaire.

\section{Participants}

The target population of this study comprised of workers on construction sites in the Ashanti Region of Ghana. Adopting purposive and accidental nonprobability sampling techniques in a multi-stage sampling, 12 construction sites were first selected. The criteria for the selection of the sites included only building construction sites active at the time of visit with many different trades working on site and that the main contractor was a large firm. The criteria set for the selection of the construction sites for the study was based on the need to collect data from construction site workers with experience from worksites where the prevalence of violence could be expected. Large construction companies tend to employ a lot of workers on their site due to the nature of projects they undertake. Construction firms in Ghana are categorized into four financial classes according to the size of individual projects they can bid for from government (Dansoh, 2005). Building construction companies come under category ' $\mathrm{D}$ ' and civil engineering companies under category ' $\mathrm{K}$ '. Each category has four financial sub-categories ' 1 ', '2', '3' and '4' which is based on the financial capacity, labour holding and expertise as well as plant holding of companies. Existing classifications thus comprise: 'D1', 'D2', 'D3' and 'D4' for building construction companies; and 'K1', 'K2', 'K3' and 'K4' for civil engineering companies. The 12 sites selected 
for the study were active sites managed by D1/K1 construction companies (large firm). Each selected site was visited on a different day and tradesmen and supervisors on site on the day and time of the visit and willing to take part in the survey were selected for the survey. This accidental sampling technique was adopted to select the respondents from each selected site for the study because, the population of workers on a construction site cannot be well defined due to issues like the complex mix of different trades and activities at any given time and workers being employed on short-term and fixed contracts. Although, nonprobability sampling has a lot of limitations due to the subjective nature in choosing the sample and thus it is not good representative of the population, it is useful especially when randomization is impossible like when the population is very large and also not well defined (Ilker et al., 2016). A total of 305 questionnaires were distributed across all 12 construction sites selected for the study, with the data collection spanning a period of 4 weeks.

\section{Data Analysis}

The data collected was refined, coded and fed into the IBM Statistical Package for Social Sciences (SPSS) AMOS for both descriptive and inferential data analysis. Mean scores and standard deviations were obtained to determine the frequently occurring violent and unsafe behaviours on the sites visited. The relationship between violent behaviour and unsafe behaviour was examined using Partial Least Squares (PLS) - Structural Equation Modelling (SEM). Modelling strategies vary from problem to problem (Medina-Borja and Pasupathy, 2007). Regression, specifically multiple regression and Chi-Square works well in model development and testing (Theory) when it involves multiple independent variables and single dependent variable. However in cases where model development and testing (Theory) involves multiple independent and multiple dependent variables, system methods such as system dynamics (SD), decision making trial and evaluation laboratory (DEMATEL), and fuzzy cognitive mapping (FCM) as well as structural equation modelling (SEM) remain very popular and powerful nonparametric predictive methodologies to uncover/confirm significant variable relationships and build the equations to feed the model (Medina-Borja and Pasupathy, 2007: Sterman, 2000). With SD, one is able to present both qualitative and quantitative descriptions of relationships between multiple independent and multiple dependent variables. DEMATEL and its variant are popularly used to identify the causeeffect relationships among several factors in a complex system (Tsui et al., 2015). FCMs are graphical representations that helps to determine the most relevant factors of a complex system and the relationships between those factors (Rodriguez-Repiso, 2007). However, all these system methods rely on the knowledge of experts (decision makers) to develop the cause and effect diagrams (Keskin, 2015). SEM is able to present quantitative descriptions of relationships between multiple independent and multiple dependent variables giving both direction of relationship (i.e. 
positive and negative) plus the extent of the relationships. There are two general approaches to SEM i.e. covariance-based structural equation modelling (CBSEM) and the component-based approach PLS (Urbach and Ahlemann, 2010). Partial Least Squares (PLS) algorithm of Structural Equation Modelling (SEM) was preferred in this study that sought to quantitatively describe the relationship between violent behaviours and unsafe behaviours on construction sites from the standpoint of construction site workers (they are not necessarily experts) because: 1) it makes lower demands on measurement scales, sample size, and residual distributions; and 2) it allows for researchers to modify models for purposes of fitness. Using SEM as a resource for formulating relationships from survey data can prove to be advantageous. SEM can be used to either reinforce or challenge preconceived notions about relationships. SEM can also help to draw associations between abstract concepts and constructs, which otherwise would have been close to impossible (Medina-Borja and Pasupathy, 2007).

Partial Least Squares (PLS) - Structural Equation Modelling (SEM) is also a method for creating predictive models when dealing with several highly collinear factors. The prominence is on predicting the responses and not necessarily on trying to comprehend the fundamental relationship between the variables. PLS is principally used to develop theories in exploratory research. For example, PLS is not usually fitting for screening out factors that have an insignificant effect on the response. However, when forecasting is the goal and there is no practical requirement to limit the number of measured factors, PLS can be a useful tool. PLS was developed in the 1960's by Herman Wold as an econometric method, but some of its most enthusiastic proponents are chemical engineers and chemometricians. In addition to spectrometric calibration, PLS has been applied to monitoring and controlling industrial processes; a large process can simply have hundreds of controllable variables and dozens of outputs. According to Hair et al. (2011), path models are diagrams used to visually show the hypotheses and variable relationships that are examined when SEM is applied. PLS path models are accurately defined by two sets of linear equations: the measurement model (also called outer model) and the structural model (also called inner model). The measurement model stipulates the relations between a construct and their indicators while the structural model stipulates the relationships between the constructs (latent variables). Before the testing of the model (i.e. the impact of violence behaviour on safety behaviour), a preliminary test of the fit of the data for the model was done using Comparative Fit Index (CFI), Goodness of Fit Index (GFI), Root Mean Square Error of Approximation (RMSEA) and Standardised Root Mean Square Residual (SRMR). This was done to give credence to the model and enhance robustness (Hair et al., 2016; Lei and Wu, 2008; Kwofie et al., 2016; Kwofie et al., 2015). 


\section{RESULTS}

Out of 305 questionnaires distributed, 207 representing $67.87 \%$ were correctly completed and retrieved. As shown in Table 3,90.3\% of the respondents were males while $9.7 \%$ represented females with most of the respondents falling between the ages of 18 to 39 years. A closer look at Table 3, reveals that almost $43 \%$ of the respondents have up to first degree or above level of education with the rest possessing various technical qualifications.

Table 3 Descriptive statistics of the survey participants

\begin{tabular}{lll}
\hline Characteristics & Frequency & Percentage (\%) \\
\hline Gender & & \\
\hline Male & 187 & 90.3 \\
Female & 20 & 9.7 \\
\hline Age (years) & & \\
\hline$<18$ & 3 & 1.4 \\
$18-28$ & 120 & 58.0 \\
$29-39$ & 80 & 38.6 \\
40-50 & 4 & 1.9 \\
\hline Educational background & & \\
\hline MPhil/MSc & 33 & 15.9 \\
BSc & 56 & 27.1 \\
Higher national diploma & 49 & 23.7 \\
Technician (CTC1,2,3) / SHS/JHS & 69 & 33.3 \\
\hline Role of respondents in their firms & & \\
\hline Site engineers/Supervisors & 59 & 28.5 \\
Carpenters & 28 & 13.5 \\
Electricians & 16 & 7.7 \\
Steel fixers & 10 & 4.8 \\
Heavy equipment operators & 5 & 2.4 \\
Masons & 59 & 28.5 \\
Labourers & 30 & 14.5 \\
\hline Working experience (years) & \multicolumn{2}{l}{} \\
\hline 1-5 & 109 & 52.7 \\
6-10 & 26 & 12.6 \\
11-15 & 13 & 6.3 \\
16-20 & 59 & 28.5 \\
\hline \hline Note: CTC = Construction technician course; SHS = Senior high school; JHS \\
= Junior high school; & \multicolumn{2}{l}{} \\
\hline \hline
\end{tabular}

It was imperative to determine the profession of the respondents to help establish how unpretentious their responses to the survey questions are. Approximately twenty nine percent (29\%) of the total number of respondents were site engineers/supervisors with the remaining working on the sites as operatives with considerable years of experience (see Table 3 ). 


\section{Occurrence of Violent Behaviours}

To evaluate the occurrence of violent situations on construction sites, it was deemed necessary and imperative to ascertain the perception of respondents on the violent situations adapted from literature (see Table 2). Respondents were asked to rate them according to their degree of occurrence on their sites using a five-point Likert scale i.e. 1 - never, 2 - rarely, 3 - sometimes, 4 - often, 5 - always. Evidence of the prevalence of the three facets of violent behaviour (i.e. physical or verbal, active or passive, and direct or indirect) identified from literature (Buss, 1961 cited in Glomb et al., 2002) can be seen from the results presented in Table 4. 'Aggressive insistence on a way of always doing things' (mean $=3.85$, standard deviation $=1.022$ ); 'Shouting at staff to get things done (mean $=3.45$, standard deviation $=1.662$ )'; 'Repeated requests giving impossible deadlines or impossible tasks' (mean $=3.34$, standard deviation $=1.224$ ); 'Hitting of co-worker' ( mean $=3.31$, standard deviation $=1.362$ ); and 'Exclusion and isolation' ( mean $=3.00$, standard deviation $=1.153$ ), were reported as frequently occurring on the sites visited. However, others like 'Sexual harassment'; 'Deliberately withholding work-related information or supplying incorrect information' and 'Slandering or maligning a worker and his/her family' were found not to be quite pervasive on the sites visited (see Table 4).

Table 4 Mean and standard deviation of occurrence of violent behaviour

\begin{tabular}{llll}
\hline \hline Violent behaviour (variables) & Mean & $\begin{array}{l}\text { Std. } \\
\text { Deviation }\end{array}$ & Rank \\
\hline \hline Aggressive insistence on a way of always doing things & 3.85 & 1.022 & $1^{\text {st }}$ \\
Shouting at staff to get things done & 3.45 & 1.662 & $2^{\text {nd }}$ \\
Repeated requests giving impossible deadlines or impossible & 3.34 & 1.224 & $3^{\text {rd }}$ \\
tasks & 3.31 & 1.362 & $4^{\text {th }}$ \\
Hitting co-worker & 3.26 & 0.999 & $5^{\text {th }}$ \\
Verbal abuse & 3.24 & 0.935 & $6^{\text {th }}$ \\
Threatening by pointing of finger & 3.09 & 1.221 & $7^{\text {th }}$ \\
Disturbing/threating phone calls & 3.01 & 1.498 & $8^{\text {th }}$ \\
Verbal or written threats & 3.00 & 1.153 & $9^{\text {th }}$ \\
Exclusion and isolation & 2.96 & 1.305 & $10^{\text {th }}$ \\
Deliberately sabotaging or impeding the performance of work & 2.95 & 1.323 & $11^{\text {th }}$ \\
Shoving or pushing & 2.95 & 1.657 & $12^{\text {th }}$ \\
Unreasonable and/or unfounded refusal of leave and training & 2.76 & 1.354 & $13^{\text {th }}$ \\
Throwing objects or vandalizing to threaten staff & 2.75 & 1.256 & $14^{\text {th }}$ \\
Obviously insulting, ostracising, boycotting or disregarding the & 2.73 & 1.741 & $15^{\text {th }}$ \\
employee & 2.69 & 1.341 & $16^{\text {th }}$ \\
Sexual harassment & 2.63 & 1.498 & $17^{\text {th }}$ \\
Deliberately withholding work-related information or & & & \\
supplying incorrect information of this kind & & \\
Slandering or maligning a worker and his/her family & & & \\
\hline \hline
\end{tabular}




\section{Occurrence of Unsafe behaviours}

Safety-related work behaviours are very accurate workplace safety indicators because according to Beus et al. (2016), they can infer both the presence and absence of safety. Unsafe behaviours are thus, actions which when exhibited by individuals have the potential to cause the occurrence of a feared outcome are proximal indicators of workplace safety because such behaviours precede the occurrence of accidents (Beus et al., 2016; Burke and Signal, 2010). For this reason, respondents were presented with fifteen (15) unsafe behaviours adapted from literature to rate their occurrence on their sites using the Likert scale of 1-5 (1 - never, 2 - rarely, 3 - sometimes, 4 often and 5-always). From Table 5, 12 out of the 15 unsafe behaviours presented to the respondents were reported to occur sometimes to always on the sites visited. It is interesting to note that the survey results showed respondents perceived 'Throwing or accidentally dropping objects from high levels' (mean $=3.91$, standard deviation $=1.233$ ); 'Working with lack of concentration' (mean $=3.63$, standard deviation $=1.370$ ); 'Leaving nails or other sharp objects protruding from timber' (mean $=3.62$, standard deviation $=1.107$ ) as the top 3 most occurring unsafe behaviours. However, 'Working under the effects of alcohol and other drugs' (mean =2.94, standard deviation $=1.634$ ); 'Working at improper speeds' ( mean $=2.87$, standard deviation $=$ 1.410); and 'Using defective equipment and tools to work' ( mean $=2.82$, standard deviation $=$ 0.951), were not seen by the respondents as frequently occurring on their sites.

Table 5 Occurrence of Unsafe Behaviours

\begin{tabular}{llll}
\hline \hline Violent situations (variables) & Mean & $\begin{array}{l}\text { Std. } \\
\text { Deviation }\end{array}$ & Rank \\
\hline \hline Throwing or accidentally dropping objects from high levels & 3.91 & 1.233 & $1^{\text {st }}$ \\
Working with lack of concentration & 3.63 & 1.370 & $2^{\text {nd }}$ \\
Leaving nails or other sharp objects protruding from timber & 3.62 & 1.107 & $3^{\text {rd }}$ \\
Improper placing and stacking of objects and materials in & 3.54 & 1.354 & $4^{\text {th }}$ \\
dangerous locations & 3.51 & 1.218 & $5^{\text {th }}$ \\
Improper lifting, handling or moving of objects & 3.51 & 1.454 & $6^{\text {th }}$ \\
Incorrect use of tools and equipment, hand tools etc. & 3.28 & 0.955 & $7^{\text {th }}$ \\
Removing safety guards from the workplace or equipment & 3.28 & 1.607 & $8^{\text {th }}$ \\
Improper positioning of tasks & 3.17 & 1.620 & $9^{\text {th }}$ \\
Improper posture for tasks & 3.14 & 1.260 & $10^{\text {th }}$ \\
Annoyance and horseplay in the workplace & 3.04 & 1.238 & $11^{\text {th }}$ \\
Ignoring to wear personal protective equipment (PPE) & & & \\
\hline \hline
\end{tabular}




\begin{tabular}{llll}
\hline \hline Failure to warn or to secure members out of danger & 3.01 & 1.231 & $12^{\text {th }}$ \\
Working under the effects of alcohol and other drugs & 2.94 & 1.634 & $13^{\text {th }}$ \\
Working at improper speeds & 2.87 & 1.410 & $14^{\text {th }}$ \\
Using defective equipment and tools to work & 2.82 & 0.951 & $15^{\text {th }}$ \\
\hline \hline
\end{tabular}

\section{Impact of Violence on Unsafe Behaviour}

\section{Composite reliability and convergent validity}

For the analysis of the impact of violent behaviour on unsafe behaviour, internal consistency reliability was initially assessed. According to Straub et al. (2004), Cronbach's alpha is the traditional criterion for internal consistency which gives an estimate of the reliability based on correlations of the observed indicator variables. Rahman et al. (2013) posited that Cronbach's alpha values must be higher than 0.7. In this study (see Table 6), Cronbach's alpha values are 0.963 and 0.970 indicating satisfactory level of internal consistency. Due to Cronbach alpha's restrictions in the population, it is more suitable to use a distinct measure of internal consistency reliability, which is called composite reliability. This reliability criterion considers the different outer loadings of the indicator variables (Straub et al., 2004). Composite reliability ranges between 0 and 1. Higher values indicate higher reliability. As can be seen from Table 6, composite reliability values were 0.967 and 0.974 indicating significant internal consistency. According to Hair et al. (2016), convergent validity is the degree to which a measure relates positively with other measures of the same construct. Average Variance Extracted (AVE) is considered alongside the outer loadings of the indicators (see Table 6). Higher outer loadings on a construct indicate that the accompanying indicators have much in common. After conducting the Outer Loading Relevance Testing Criterion, the entire construct had AVE higher than 0.50. Hence, the data satisfies the requirement of convergent validity.

Table 6 Composite reliability and convergent validity

\begin{tabular}{llll}
\hline \hline Constructs & Cronbach's Alpha & Composite Reliability & AVE \\
\hline \hline Unsafety Behaviour & 0.963 & 0.967 & 0.664 \\
Violence & 0.970 & 0.974 & 0.689 \\
\hline \hline
\end{tabular}




\section{Discriminant validity}

Discriminant validity is the degree to which a construct deviates from other constructs by empirical standards (Hair et al., 2016). The Fornell-Larcker criterion is used to assess the discriminant validity. From Table 7, it can be concluded that the constructs in the study attained a significant reliability and validity.

Table 7 Fornell-Larcker Criterion

\begin{tabular}{lll}
\hline \hline Constructs & Unsafe Behaviour & Violence \\
\hline \hline Unsafety behaviour & 0.815 & \\
Violence & 0.968 & 0.830 \\
& & \\
\hline \hline
\end{tabular}

Table 8 Results of the Fit indexes

\begin{tabular}{cccc}
\hline \hline Fit Indexes for Model testing & & & \\
\hline \hline Fit Index & Cut-off value & Estimate & Remarks \\
\hline \hline CFI & $\begin{array}{c}\mathrm{x} \geq 0.90 \text { (acceptable) } \\
\mathrm{x} \geq 0.95 \text { (good fit) }\end{array}$ & 0.962 & Good fit \\
& $\mathrm{x} \geq 0.90$ (acceptable) \\
$\mathrm{x} \geq 0.95$ (good fit) & 0.955 & Good fit \\
\hline GFI & $\mathrm{x} \leq 0.08$ (acceptable) & 0.080 & Acceptable fit \\
& $\mathrm{x} \leq 0.05$ (good fit) & & \\
\hline SRMR & & & Good fit \\
& $\mathrm{x} \leq 0.08$ (acceptable) $\mathrm{x} \leq$ \\
\hline RMSEA & 0.05 (good fit) & 0.022 & Good fit \\
\hline \hline
\end{tabular}

The results for the fit indexes presented in Table 8 revealed that CFI (0.962), GFI (0.955) and RMSEA (0.022) were all greater than the conventional minimum i.e. cut-off values thus are 
deemed as good fit for the model. The SRMR value was 0.080. This could be interpreted as an acceptable fit. According to Iacobucci (2010) and Hair et al. (2016), a good fit and an acceptable fit for two fit criteria for incremental and absolute fit indices are good support for model fit to a data. Additionally, the p-value was 0.033 which was less than 0.05 . This suggest that the model is significant, hence, from the results can be deemed an accurate representation of reality and well supported.

\section{Coefficient of determination $\left(R^{2}\right.$ value)}

The $\mathrm{R}^{2}$ value is the most predominantly used criteria in evaluating structural models. It measures the accuracy of the predictions derived (Hair et al., 2016). There are no rules of thumb for acceptable $\mathrm{R}^{2}$ values, however according to Hair et al. (2016) $0.75,0.50$ or 0.25 can be designated as substantial, moderate or weak $\mathrm{R}^{2}$ values. In this study, the $\mathrm{R}^{2}$ value of the dependent construct (Unsafe behaviour) is 0.938 which specifies that the regression of the independent construct (Violent behaviour) was very substantial, accounting for about $94 \%$ of the variance in unsafe behaviour (see Figure 2). Outer loadings of violent behaviour and unsafe behaviour attributes are indicated in Table 9.

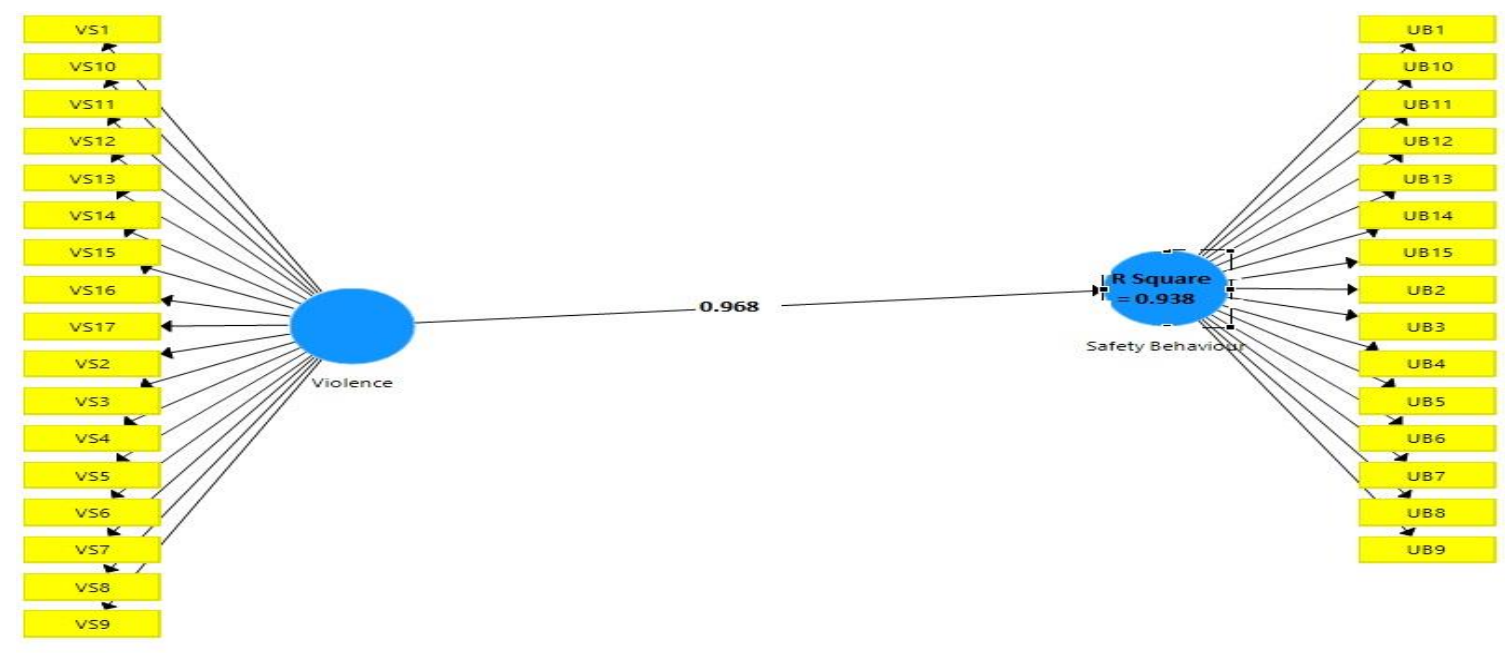

Figure 2. Reflective PLS-SEM Structural Model between violent behaviour and unsafe behaviour 
Table 9 Outer loadings of violence and safety behaviour attributes

\begin{tabular}{|c|c|c|}
\hline & Safety Behaviour & Violence \\
\hline UB1 & 0.721 & \\
\hline UB10 & 0.667 & \\
\hline UB11 & 0.822 & \\
\hline UB12 & 0.902 & \\
\hline UB13 & 0.889 & \\
\hline UB14 & 0.896 & \\
\hline UB15 & 0.768 & \\
\hline UB2 & 0.823 & \\
\hline UB3 & 0.954 & \\
\hline UB4 & 0.874 & \\
\hline UB5 & 0.834 & \\
\hline UB6 & 0.657 & \\
\hline UB7 & 0.714 & \\
\hline UB8 & 0.887 & \\
\hline UB9 & 0.743 & \\
\hline VS1 & & 0.881 \\
\hline VS10 & & 0.772 \\
\hline VS11 & & 0.972 \\
\hline VS12 & & 0.829 \\
\hline VS13 & & 0.546 \\
\hline VS14 & & 0.954 \\
\hline VS15 & & 0.801 \\
\hline VS16 & & 0.758 \\
\hline VS17 & & 0.561 \\
\hline VS2 & & 0.737 \\
\hline VS3 & & 0.914 \\
\hline VS4 & & 0.885 \\
\hline VS5 & & 0.891 \\
\hline VS6 & & 0.829 \\
\hline VS7 & & 0.882 \\
\hline VS8 & & 0.870 \\
\hline VS9 & & 0.886 \\
\hline
\end{tabular}




\section{DISCUSSION}

The construction industry remains tagged as one of the most unsafe industries and this is attributed to its safety statistics expressed in terms of accidents and injuries which remain alarmingly high. As evident from this study, safety management on construction sites remains a major challenge. The results from this study agree with studies such as that of Chan et al. (2005) about the prevalence of unsafe working practices on construction sites. Unsafe behaviours such as 'Throwing or accidentally dropping objects from height, lack of concentration whiles working, poor housekeeping, poor ergonomics, horse playing, and ignoring to wear personal protective equipment (PPE) were commonplace on all construction sites visited in this study (See Table 5). In studies reported in the Canada (Silliker, 2015), USA (Wang et al., 2017), and Hong Kong (Li et al., 2019), it has been revealed that throwing or accidentally dropping objects from a height has been a huge safety concern for many years. There have been reported cases of about 8,609 injuries from this unsafe behaviour in Canada (Silliker, 2015), 804 deaths of construction workers between 2011 and 2015 in the USA (Wang et al., 2017), and many reported court cases on injuries resulting from this unsafe behaviour in Hong Kong ( $\mathrm{Li}$ et al., 2019). The lack of concentration while working has also been identified as an unsafe behaviour among construction tradesmen (Bhole, 2016). Lack of concentration on the construction site mostly result from fatigue or communicating with fellow colleagues whiles working. Since construction work can be physically, mentally, and emotionally demanding, every missed hour of rest can cause an employee to suffer many disorders of which lack of concentration plays a key role. This unsafe behaviour should therefore be prevented as much as possible since it has the potential to result in accidents, near misses and dangerous occurrences. The dangers posed by all the other identified unsafe behaviours are provided in the literature sources already cited (see Table 2).

A construction site like any workplace is a place where individuals are exposed to both physical violence and verbal aggression. Workplace violence is therefore not new (LeBlanc and Kelloway, 2002) and neither is it just peculiar to construction. Conditions on a typical construction site undoubtedly promote workplace violence and aggression. Results from this study confirmed aggressive behaviours like shouting, shoving or pushing, hitting, verbal abuse, threatening by pointing of finger and outright bullying were commonplace at the sites visited.

The frequent occurrence of violence at the workplace has obviously some negative consequences.

One common feature in literature on negative outcomes of workplace violence is poor physical and emotional well-being of the victims (see Dupre' and Barling, 2003; Walsh and Clarke, 2003; LeBlanc and Kelloway, 2002). Victims are often found to be both physically and mentally stressed. Such workers often find it difficult to concentrate on their jobs and follow procedure because the 
violent situations they experience causes them to have lower job and life satisfaction, lower normative and affective commitment, and other forms of psychological distress (Tepper, 2000).

The substantial positive correlation between violent behaviour and unsafe behaviour reported in this paper could be due in part to the emotional experience of the victim also known as affective experience. Weiss and Cropanzano's (1996) work on Affective Events Theory (AET) explain emotional experience at the workplace by concentrating on the structure, causes, and consequences of affective experiences at work. They examined the backgrounds of employees' experiences of affective work events and the affective, attitudinal, and behavioural reactions to these events. According to their AET, work environment features stimulate the occurrence of positive or negative affective work events. Experiencing these events leads to affective reactions that in turn leads to affective-driven behaviours and work attitudes. Work attitudes impact judgment-driven behaviours. The affective-driven behaviours are direct consequences of affective experiences. The judgment-driven behaviours are moderated by work attitudes and to some extent individual differences. From the construction sites visited, environmental features such as the stressful nature of work and exposure to harsh weather conditions as well as the individual differences of the workers could be triggers for violent behaviours. For instance, a worker working at height (culprit), and who is very tired may lose control over the work being undertaken. If care is not taken, such a worker could accidentally drop an object which has the potential to hit a fellow worker (victim). If this victim does not restrain himself and decides to confront the culprit, there could be the tendency for violence to occur on the site. If this violence is not curtailed, there is the tendency for it to create other unsafe behaviours (like those identified in Table 5) among other colleagues on the site, and the problem goes on and on. The prevalence of violent behaviour then could lead to negative affective events amongst the worker. This could take expression in disagreements among co-workers and aggressive behaviours such as anger and frustration. According to AET, this affective experience could then lead to two types of effects i.e. affect-driven behaviours and affective influencing work attitudes. These effects ultimately affect judgement-driven behaviours. This is where it becomes clear why construction workers who suffer violence could fail to exhibit good judgement-driven behaviour which results in poor safety on site. The affective nature of violent behaviour can result in even the perpetrator also now failing to exhibit good affectivedriven behaviour. So, the high positive impact of violent behaviour on unsafe behaviour reported

in the study could be due to how both victims and perpetrators of violent acts on sites all tend to have their judgement-driven behaviours significantly affected.

\section{CONCLUSION AND RECOMMENDATIONS}

This study was conducted to examine the relationship between violent behaviour and unsafe behaviour among workers on construction sites. A list of seventeen (17) violent behaviours and 15 
unsafe behaviours were adapted from literature and presented to 305 construction site workers in a survey undertaken on 12 active construction sites in the Ashanti region of Ghana. Data obtained from the survey was analysed using the mean score ranking (to rank the frequency of occurrence of the violent behaviours and the unsafe behaviours) and the Partial Least Square-Structural Equation Modelling (PLS-SEM) technique (to examine the relationship between violent behaviour and unsafe behaviour).

The results from the mean score ranking suggests that the often-occurring violent behaviours on the construction sites are 'aggressive insistence on a way of always doing things', 'shouting at staff to get things done', 'repeated requests giving impossible deadlines or impossible tasks', 'hitting', and 'verbal abuse'. With regards to unsafe behaviours, 'throwing or accidentally dropping objects from high levels', 'lack of concentration whiles working', 'leaving nails or other sharp objects protruding from timber', 'improper placing and stacking of objects and materials in dangerous locations' 'improper lifting, handling or moving of objects' were observed as most frequently occurring on site. Again, when the Partial Least Squares-Structural Equation modelling was used to quantify the impact of the independent variables (the 17 attributes of violence) on the dependent variables (the 15 unsafe behaviours), the findings suggested that the violent behaviours have a substantial significant positive relationship with the unsafe behaviours. Results from this study provides empirical evidence lacking in literature about the influence of violent behaviour on unsafe behaviour of construction workers. Most previous studies into violent behaviour at the workplace have tended to look at it as an effect or outcome and not an action that has repercussions meaning that literature abounds in causes, frequency and nature of workplace violence but lacking in the outcome of workplace violence especially in the case of construction workers. The findings from this study therefore have strong implications for construction site safety management since it puts forward another important dimension of the problem. Both victims and perpetrators of violent acts on sites all tend to have their judgement-driven behaviours significantly affected.

Although it is unlikely that construction site violence can be eradicated, acknowledging and understanding its impact on overall safety performance on a project will lead to more effective interventions on site. There is ample indication that individual differences, particularly the traits of hostility and impulsiveness, are good forecasters of workplace violence. Therefore, selecting out those who are notably both hostile and impulsive usually is suggested as a good way to reduce the occurrence of violence at workplaces. Given the evidence from this study, selecting the right mix of workers through some screening could be a means to improve safety on construction sites. Therefore, using selection tools to screen out potentially aggressive individuals as a potential aggression reduction method is recommended. However, this approach only addresses potential individual differences antecedents of workplace aggression, neglecting situational precursors. Training and education on emotional self-regulation can also help reduce incidents of construction site violence. Interventions such as including violence at workplace as a topic in safety orientation programmes can help improve the situation. Such training will get workers aware of the issue and get them to think about their reactions and behaviours while on site. Individual worker 
characteristics needs to be considered in designing approaches to create awareness and to effectively manage the issue of violence on the site. Policies and guidelines on worksite violence need to be developed and promoted to help encourage a violent free culture on site.

Finally, a strong case can be made based on the results reported in this paper for the need for more focus on studies into violence on construction sites. This is an area that presently has not benefitted from extensive studies into its various complexities and repercussions. This is, however, needed to fully understand the impact of violence on safety management and to generally help deal with the problem of violence on construction sites. This study only determined the frequently occurring violent and unsafe behaviours witnessed on the entire site and not what various groups (e.g. labourers, tradesmen, site engineers, etc.) on the site are engaged in. Future studies can therefore investigate which violent and unsafe behaviours are often exhibited by these various groups on site and compare the degree of relationship between violent behaviour and unsafe behaviour among the groups. This would provide project managers and safety officers with an important tailoring consideration in their efforts at addressing the problems of violent and unsafe behaviours on construction sites.

\section{REFERENCES}

Abdelhamid, T. S. and Everett, J. G. (2000). 'Identifying Root Causes of Construction Accidents' Construction Engineering Management, 126(1): 52-60.

Adebayo, M.A. and Emoh, F.I. (2019). "Examination of the application of health and safety plan on construction sites in Lagos State, Nigeria". British Journal of Environmental Sciences, 7(4), pp. 1-30.

Ahmad, J., Khan, M.E., Mozumdar, A. and Varma, D.S. (2016). "Gender-based violence in rural Utter Pradesh, India: Prevalence and association with reproductive health behavours". Journal of Interpersonal Violence, 31(19), pp. 3111-3128.

Ajzen, I. (1991). "The Theory of Planned Behaviour". Organizational Behaviour and Human Decision Processes, 50(2), pp. 179-211.

Aksorn, T. and Hadikusumo, B. H. W. (2007). 'The Unsafe Acts and the Decision-to-Err Factors of Thai Construction Workers'. Journal of Construction in Developing Countries, 12(1), pp. $1-25$.

Ansorg, N. and Gordon, E. (2018). "Co-operation, contestation and complexity in post-conflict security sector reform". Journal of Intervention and State building, 13 (1), 2-24.

Asilian-Mahabadi, H., Khosravi, Y., Hassazadeh-Rangi, N., Hajizadeh, E. and Behzaden, A.H. (2018). "Factors affecting unsafe behaviour in construction projects: development and 
validation of new questionnaire". International Journal of Occupational Safety and Ergonomics, Available https://doi.org/10.1080/10803548.2017.1408243.

Aytac, S. (2015). "The sources of stress, the symptoms of stress and anger styles as a psychosocial risk at occupational health and safety: A case study on Turkishj Police Officers". Procedia Manufacturing, 3(2015), pp. 6421-6428.

Baerendes, V.R. and Baerends, G.P (1979). "The morphogenesis of the behaviour of the domestic cat: With special emphasis on the development of prey-catching. New York, N.Y.: Amsterdam.

Bandura, A. (1973). “Agression: A social learning analysis”. New Jersey, Prentice Hall, USA.

Benish-Wieisman, M. (2015). "The interplay between values and aggression in adolescence: A longitudinal study”. Dev. Psychol., 51, 677-687.

Benish-Wieisman, M. and McDonald, K.I. (2015). "Private self-conscious and gender moderate how adolescents'values relate to aggression”. Soc. Dev. 24, 766-781.

Berhanu, F., Gebrehiwot, M. and Gizaw, Z. (2019). "Workplace injury and associated factors among construction workers in Gondar town, Northwest Ethipia”. BM,C Musculoskeletal Disorders, 20(2019), pp. 1-9.

Berkowitz, L. (1994). 'Is Something Missing? Some observations prompted by the cognitiveneoassociationist view of anger and emotional aggression'. In L. R. Huesmann (Ed.), Aggressive behaviour: Current perspectives. New York: Plenum Press.

Berkowitz, L. (1974). "Some determinants of impulsive aggression: Role of mediated associations with reinforcement of aggression”. Psychological Review, 81, pp. 165-176.

Beus, J.M., McCord, M.A., Zohar, D. (2016). 'Workplace safety: A review and research synthesis'. Organisational Psychology Review, 6(4):352-381.

Bhole, S.A. (2016). "Safety problems and injuries on construction sites: A review". International Journal of Engineering and Techniques, 2(4), pp. 24-25.

Bilsky, W. and Hermann, D. (2016). "Individual values and delinquency: on considering universals in the content and structure of values". Psychol. Crime Law, 22, pp. 921-944.

Burke, M.J. and Signal, S.M. (2010). 'Workplace safety: A multilevel, interdisciplinary perspective'.In Hui Liao, Joseph J. Martocchio, Aparna Joshi (ed.) Research in Personnel and Human Resources Management Volume 29, pp. 1-47.

Burton, L. (2017) Refusal to wear PPEs : Guidance for employers. Available at: https://www.highspeedtraining.co.uk/hub/refusal-to-wear-ppe/, accessed 30 April 2020

Buss, A.H. (1961). “The psychology of aggression”. New York: Wiley 
Boyle, M. and McKenna, L. (2017). "Paramedic student exposure to workplace violence during clinical placements- A cross-sectional study", Nurse Education in Practice, 22 (2017), pp. 9397.

Cavazza, N. and Serpe, A. (2009). "Effects of safety climate on safety norm violations: exploring the mediating role of attitudinal ambivalence toward personal protective equipment". Journal of Safety Research, 40(4), pp. 277-283.

Cermelli, D., Pettinato, M., Curro, F. and Fabiano, B. (2019). "Major accident prevention: A construction site approach for pro-active management of unsafe conditions". Chemical Engineering Transactions, 74(2019), 1387-1392.

Chappell, D. and Di Martino, V. (2000). "Violence at work". $2^{\text {nd }}$ Edition, International Labour Organisation, Geneva.

Chan, A.P.C., Wong, F.K.W., Chan, D.W.M., Yam, M.C.H., Tam, C.M., and Ng, J.W.S. (2005). 'From Attitude to Culture - Effect of Safety Climate on Construction Safety'. Report of Construction Safety Research Group. Hong Kong Polytechnic University.

Choudhry, R.M. (2014). 'Behaviour-based safety on construction sites: a case study'. Accident Analysis and Prevention, 70:14-23.

Choudhry, R. and Fang, D. (2008). 'Why operatives engage in unsafe work behaviour: Investigating factors on construction sites'. Safety Science, Volume 46 No. 4, p. 566-584.

Connor, M. and Armitage, C.J. (2009). "Extending the theory of planned behaviour: a review of avenues for further research". Journal of Applied Social Psychology, 28(15), pp. 717-738.

Copeland, D. and Henry, M. (2018). "The relationship between workplace violence, perceptions of safety, and professional quality of life among emergency department staff members in a Level 1 Trauma Centre”. International Emergency Nursing, 39 (2018), pp. 26-32.

Cullinan, J., Hodgins, M., Hogan, V., McDermott, M. and Walsh, S. (2019). "Bullying and workrelated stress in the Irish workplace". Societies, 9(1), pp. 1-15.

Dansoh, A. (2005). Strategic planning practice of construction firms in Ghana. Construction Management and Economics, 23(2), 163-168.

Di Martino, V., Hoel, H. and Cooper, C. L. (2003). 'Preventing Violence and Harassment in the Workplace'. Luxembourg: Office for Official Publications of the European Communities.

Dodoo, J.E. and Al-Samarraie, H. (2019). 'Factors leading to unsafe behaviour in the twenty first century workplace: a review'. Management Review Quarterly, Published online: 23 February 2019. 
Dong, X.S., Wang, X. and Largay, J.A. (2015). 'Occupational and non-occupational factors associated with work-related injuries among construction workers in the USA'. International Journal of Occupational and Environmental Health, 21(2): 142-150.

Dupre', K. E., and Barling, J. (2003). 'Workplace aggression'. In A. Sagie, S. Stashevsky, and M. Koslowsky (Eds), Misbehaviour and dysfunctional attitudes in organizations (pp. 13-32). Hampshire: Palgrave Macmillan.

Einarsen, S. (2000). 'Harassment and bullying at work: A review of the Scandinavian approach'. Aggression and Violent Behaviour, 5, 379-401.

Einarsen, S., Raknes, B.I., Mathiesen, S.B. \& Hellesøy, O.H. (1994) Mobbing og Harde Personkonflikter. Helsefarlig samspill på arbeidsplassen. Sigma Forlag, London.

Environmental Health and Safety Office, EHSO, (2017). Tool box talks. Emory University. Available at: www.ehso.emory.edu, accessed 30 April 2020.

Erdis, E., Genç, O. and Aydinli, S. (2019). "Mobbing on construction professionals: causes, consequences and precautions". International Journal of Construction Management, Avaialble https://doi.org/10.1080/15623599.2019.1602579.

Estévez, E., Jiménez, T.T. and Moreno, D. (2018). Aggressive behaviour in adolescence as a predictor of personal, family and school adjustment problems. Psicothema, 30(1), PP. 66-73.

European Agency for Safety and Health at Work, EASHW, (2010). "Workplace violence and harassment: a European picture". Luxembourg Publications Office of the European Union.

Fam, I.M., Nikoomaram, H., Soltanian, A. (2012). 'Comparative analysis of creative and classic training methods in health, safety and environment participation improvement'. J Loss Prev Process Ind, 25:250-253.

Fang, D., Zhao, C. and Zhang, M. (2016). 'A cognitive model of construction workers' unsafe behaviours. Journal of Construction Engineering and Management, 142(9):04016039.

Fargnoli, M. and Lombardi, M. (2019). "Preliminary human safety assessment for the improvement of the behavioural aspects of safety climate in the construction industry", Buildings, 9(2019), pp. 1-18.

Fleming, M., Lardner, R. (2002). 'Startegies to promote safe behaviour as part of a health and safety management system, prepared by the Keil Centre for the Health and Safety. HSE Books.

Garber, E.A. (2017). "OSHA and workplace violence: What contractors need to know. Available http://buildsmartbradley.com, accessed 13 March 2020. 
Ghasemi, F., Kalatpour, O., Moghimbeigi, A., Mohhamadfan, I. (2018). 'A path analysis model for explaining unsafe behaviour in workplaces: the effect of perceived work pressure'. International journal of occupational safety and ergonomics, 24(2):303-310.

Glomb, T. M., Steel, P. D., and Arvey, R. D. (2002). 'Office sneers, snipes, and stab wounds: Antecedents, consequences, and implications of workplace violence and aggression'. In R. Lord, R. Klimoski, and R. Kanfer (Eds.), Frontiers of industrial and organizational psychology: Emotions and work: 227-259. San Francisco: Jossey-Bass.

Goh, Y.M. and Binte Sa'adon, N.F. (2016). "Cognitive factors influencing safety behaviour at height: a multimethod exploratory study". Journal of Construction Engineering and Management, 141(6), 04015003.

Grabowski, M., Ayyalasomayajula, P., Merrick, J., Harrald, J.R., FRoberts, K. (2007). 'Leading indicators of safety in virtual organisations'. Safety Science, 45:1-13-1043.

Groenewold, M.R., Sarmiento, R.F.R, Vanoli, K., Raudabaugh, W., Nowlin, S. and Gomaa, A. (2017) Workplace violence injury in 106 US hospitals participating in the Occupational Health and Safety Network, 2012-2015”. American Journal of Industrial Medicine, 61 (2018), pp. 157-166.

Grytnes, R., Tutt, D.E., Andersen, L.P.S. (2020). "Developing safety cooperation in construction: between facilitating independence and tightening the grip". Construction Management and Economics, Available https://doi.org/10.1080/01446193.2020.1726978.

Guo, S., He, J., Li, J. and Tang, B. (2020). "Exploring the impact of unsafe behaviours on building construction accidents using a Bayesian Network". International Journal of Environmental Research and Public Health, 17(2020), pp. 1-15.

Han, S., Saba, F., Lee, S., Mohamed, Y., Pena-Mora, F. (2014). 'Toward an understanding of the impact of production pressure on safety performance in construction operations'. Accident Analysis and Prevention, 68:106-116.

Hair, J. F., Hult, G. T. M., Ringle, C. and Sarstedt, M. (2016). 'A primer on partial least squares structural equation modelling (PLS-SEM)’. s.l.:Sage Publications.

Hair, J.F., Jr., Ringle, C.M. and Sarstedt, M. (2011). 'PLS-SEM: Indeed, a silver bullet'. Journal of Marketing theory and Practice, 19(2), pp.139-52. https://doi.org/10.2753/mtp1069$\underline{6679190202}$

Haslam, R.A., Hide, S.A., Gibb, A.G.F., Gyi, D.E., Pavitt, T., Atkinson, S., Duff, a.R. (2015). 'Contributing factors in construction accidents. Applied Ergonomics, 36:401-415.

Health and Safety Executive (HSE) (2019). 'Strategies to Promote Safe Behaviour as Part of a Health and Safety Management System'. UK. 
Hinze, J., Thurman, S., Wehle, A. (2013). 'Leading indicators of construction safety performance'. Safety Science, 51:23-28.

Hojati, A. (2018) Eight best practices to improve construction site safety. Available at: https://esub.com/improve-construction-site-safety/, accessed 30 April 2020.

Hsieh, I-Ju and Chen, Y.Y.(2017) Determinants of aggressive behaviour: Interactive effects of emotional regulation and inhibitory control, PLOS ONE, 12 (4) e0175651.

Huang, Y-H. and Yang, T-R. (2019). Exploring on-site safety knowledge transfer in the construction industry. Sustainability, 11 (2019), pp. 1-16.

Keskin, G.A. (2015), "Using integrated fuzzy DEMATEL and fuzzy C: means algorithm for supplier evaluation and selection", International Journal of Production Research, Vol. 53 No. 12 , pp. 3586-3602.

Kwofie, T. E., Adinyira, E. and Fugar, F (2016) "Modelling the effect of housing design unit contract packaging on mass housing project team communication performance". Journal of Construction in Developing Countries, 21(1): 35-50. doi: 10.21315/jcdc2016.21.1.3

Kwofie, E., Fugar, F., and Adinyira. E., (2015) "Contribution of multiple construction site management features to project team communication effectiveness: the case of mass housing projects" Engineering Project Organization Journal, DOI:10.1080/21573727.2015.1102132

Iacobucci, D. (2010) Structural equations modelling: Fit Indices, sample size, and advanced topics. Journal of Consumer Psychology, 20, pp90-98

Ilker E., Sulaiman A. M. and Rukayya S. A. (2016) Comparison of Convenience Sampling and Purposive Sampling. American Journal of Theoretical and Applied Statistics. Vol. 5, No. 1, 2016, pp. 1-4. doi: 10.11648/j.ajtas.20160501.11

Jiang, Z., Fang, D., Zhang, M. (2014). 'Understanding the causation of construction workers' unsafe behaviours based on system dynamics modelling'. Journal of Management in Engineering, 31(6), 040140991-14.

Kao, K-Y., Spitzmueller, C., Cigularov, K. and Thomas, C.L. (2019). 'Linking safety knowledge to safety behaviours: a moderated mediation of supervisor and worker safety attitudes. European Journal of Work and Organizational Psychology, 28(2): 206-220.

Kennedy, G. (2016). "NUCA safety management: Workplace violence in the construction industry. Available http://utilitycontractoronline.com accessed 14 March 2020.

Khosravi, Y., Asilian-Mahabadi, H., Hajizadeh, E., Hassanzadeh-Rangi, N., Bastani, H., Behzadan, A.H. (2014). 'Factors influencing unsafe behaviours and accidents on construction sites: a review'. International Journal of Occupational Safety Ergonomics, 20(1): 111-125. 
Lawton, P. (2014) Material handling that stacks up to safety requirements. Available at: https://ehsdailyadvisor.blr.com/2014/05/material-handling-that-stacks-up-to-safetyrequirements/, accessed 30 April 2020.

LeBlanc, M. M., and Kelloway, E. K. (2002). 'Predictors and outcomes of workplace violence and aggression'. Journal of Applied Psychology, 87, 444-453.

Lee, H-L., Han, C-Y., Redley, B., Lin,. C-C., Lee, M-Y. and Chang, W. (2020). "Workplace violence against emergency nurses in Taiwan: A cross-sectional study, Journal of Emergency Nursing, 46 (1), pp. 66-71.

Lehtola, M.M., Van Der Molen, H.F., Lappalainen, J., Hoonakker, P.L.T., Hsiao, H., Haslam, R.A., Hale, A.R. and Verbeek, J.H. (2008). "The effectiveness of interventions for preventing injuries in the construction industry-a systematic review". American Journal of Preventive Medicine, 35, 77-85.

Lei, P. and Wu, Q. (2008) Introduction to Structural Equation Modeling: Issues and Practical Considerations. An NCME Instructional Module, pp. 33-43

Leymann, H. and Gustafsson, A. (1996). 'Mobbing at work and the development of post-traumatic stress disorders'. European Journal of Work and Organizational Psychology, 5:2, 251-275, DOI: $10.1080 / 13594329608414858$

Li, R.Y.M., Chau, K.W. and Zeng, F.F. (2019). "Ranking of risks for existing and new building works". Sustainability, 11(2019), pp. 1-26.

Liao, P-C, Liu, B., Wang, Y., Wang, X., Ganbat, T. (2017). 'Work paradigm as a moderator between cognitive factors and behaviours: a comparison of mechanical and rebar workers'. KSCE Journal of Civil Engineering, 21(7):2514-2525.

Lingard, H., Zhang, R., Harley, J., Blismas, N. and Wakefield, R. (2019). "Work and Safety Culture". Available http://www.rmit.edu.au/research/health-safety-research, accessed 17 March 2020.

Lipscomb, H.J., Dale, A.M., Kaskutas, V., Sherman-Voellinger, R., Evanoff, B. (2008). 'Challenges in residential fall prevention: Insight from apprentice carpenters'. American Journal of Industrial Medicine, 51(1), 60-68.

Li, N., Zhang, L. Xiao, G., Chen, J. and Lu, Q. (2019). “The relationship between workplace violence, job satisfaction and turnover intention in emergency nurses". International Emergency Nursing, 45 (2019), pp. 50-55.

Li, Z., Lv, X., Zhu, H. and Sheng, Z. (2018). "Analysis of complexity of unsafe behaviour in construction teams and a multiagent simulation". Hindawi Complexity (2018), pp. 1-15.]

Liang, K., Fung, I.W.H., Xiong, C. and Luo, H. (2019). "Understanding the factors and the corresponding interactions that influence construction worker safety performance from a 
competency-model-based perspective: Evidence from scaffolders in China”. International Journal of Environmental Research and Public Health, 16(2019), pp. 1-23.

Lioa, P-C., Luo, X., Wang, T., Su, Y. (2016). 'The mechanism of how design failures cause unsafe behaviour: The cognitive reliability and error analysis method'. Procedia Engineering, 145(2016):715-722.

Lippel, K. (2016). "Addressing occupational violence: An overview of conceptual and policy considerations viewed through a gender lens”. International Labour Office, Geneva.

Liu, H., Zheng, J., Liu, K., Liu, X., Wu, Y., Wang, and You, L. (2019). "Workplace violence against nurses, job satisfaction, burnout and patient safety in Chinese hospitals". NURS OUTLOOK 67 (2019), pp. 558-566.

Liu, X., Huang, G., Huang, H., Wang, S., Xiao, Y., Chen, W. (2015). 'Safety climate, safety behaviour, and worker injuries in the Chinese manufacturing industry'. Safety Science, 78:173178.

Lop, N.S.B, Salleh, N.M., Zain, F.M.Y. and Saidin, M.T. (2019). "Ergonomic risk factors and their association with musculoskeletal disorders among Malaysian construction trade workers: Concreters". International Journal of Academic Research in Business and Social Sciences, 9(9), pp. 1269-1282.

Malik, O.F., Schat, A.C.H., Shahzad, A., Raziq, M.M. and Faiz, R. (2018). "Workplace psychological aggression, job stress and vigor: A test of longitudinal effects". Journal of Interpersonal Violence, Available https://doi.org/10.1177/0886260518770650.

Mason, S. (1997). 'Procedural violations-causes, costs and cures'. Human factors in safety-critical systems, 1:287-318.

Marques, P.H., Jesus, V., Olea, S.A., Vairiinhos, V. and Jacinto, C. (2014). The effect of alcohol and drugs testing at the workplace on individual's occupational accident risk. Safety Science, 68(2014), pp. 108-120.

Medina-Borja, A., and Pasupathy, K. S. (2007). Uncovering complex relationships in system dynamics modeling: Exploring the use of CART, CHAID and SEM. In Proceedings of the 25th International Conference of the System Dynamics Society, (Boston, USA) (pp. 1-24).

Meisler, G., Drory, A. and Vigoda-Gadot, E. (2019). "Perceived organisational politics and counterproductive work behaviour: The mediating role of hostility". Personnel Review, Vol.ahead-of-print No.ahead-of-print. Available https://doi.org/10.1108/PR-12-2017-0392.

Messner, S. (1988). "Research on cultural and socioeconomic factors in criminal violence". Psychiatric Clinics of North America, 11(4), pp. 511-525. 
Minnesota Advocates for Human Rights (2003). Stop violence against women: Sexual Harassment. Available at: http://hrlibrary.umn.edu/svaw/harassment/explore/3causes.htm, accessed 1 May 2020.

Moan, I.S. and Rise, J. (2006). "Predicting smoking reduction among adolescents using using an extended version of the theory of planned behaviour". Psychology and Health, 21(6), pp. 717738.

Mohammadfam, I., Ghasemi, F., Kalatpour, O., Moghimbeigi, A. (2017). 'Constructing a Bayesian network model for improving safety behaviour of employees at workplaces'. Applied Ergonomics, 58:35-47.

Mosadeghrad, A.M., Ferlie, E. and Rosenberg, D. (2014). "A study of relationship between job stress, quality of working life and turnover intention among hospital employees". HealthServices Management Research, 24(4), pp. 170-181.

Mustapha, Z., Aigbavboa, C. and Thwala, W.D. (2015). "Conceptualised integrated health and safety compliance model for the Ghanaian construction industry". $6^{\text {th }}$ International Conference on Engineering, Project, and Production Management, Gold Coast, Astralia, pp. 1-12.

Nadhim, E.L. (2019). "Investigating the relationship between safety climate and safety performance of retrofitting works". A Doctoral Thesis submitted to the Faculty of Civil Engineering and Built Environment Science and Engineering, Queensland University of Technology.

Nadhim, E.A., Hon, C., Xia, B., Stewart, I. and Fang, D. (2016). "Falls from heights in the construction industry: A critical review of the scientific literature". International Journal of Environmental Research and Public Health, 13(2016), pp. 1-20.

Namie, G., and Namie, R. (2000). 'Workplace bullying: The silent epidemic'. Employee Rights Quarterly, 1(2), 1-12.

Navarro-Astor, E., Roman-Onsalo, M. and Infante-Perea, M. (2017), "Women's career development in the construction industry across 15 years: main barriers", Engineering, Design and Technology, pp. 199-221.

Nawaz, A., Su, X., Din, Q.M.U., Khalid, M.I., Bilal, M. and Shah, S.A.R. (2020). "Identification of the health and safety factors involved infrastructure projects in developing countries-A sequential mixed method approach of OLMT-Project". International Journal of Environmental Research and Public Health, 17(2020), pp. 1-20.

Neuman, J. H., and Baron, R. A. (1998). 'Workplace violence and workplace aggression: Evidence concerning specific forms, potential causes, and preferred targets'. Journal of Management, 24, 391-419. 
Nieto-Gutierrez, W., Toro-Huamanchumo, C.J., Taype-Rondan, A., Timan-Ruiz, R., Diaz, A., Jumpa-Armas, D. and Escobedo-Palza, S. (2018). Workplace violence by specialty among Peruvian medical residents. PLOS ONE, 13 (11), pp. e0207769.

NHS Health Scotland (2017). Managing occupational violence and aggression in the workplace: Tools and Strategies. NHS Health Scotland, Edinburgh, Scotland.

NTWorkSafe, (2015). NTWorkSafe. [Online] Available at: worksafe.nt.gov.au [Accessed 28 April 2017].

Nyede-Byakika, S. (2016). 'Occupational safety and health issues on road construction sites in sub-saharan Africa: A Case study from Uganda'. African Journal of Science, Technology, Innovation and Development, 8(3): 256-263.

Olson, N.K. (1994). "Workplace violence: Theories of causation and prevention strategies". AAOHN Journal, 42(10), pp. 477-482.

Oswald, D., Sherratt, F. and Smith, S. (2015). "Exploring factors affecting unsafe behaviours in construction.'In; Procs $29^{\text {th }}$ Annual ARCOM Conference, 2-4 September 2013, Reading, UK, Association of Researchers in Construction Management, pp. 335-344.

Payne, S.C., Bergman, M.E., Beus, J.M., Rodriguez, J.M., Henning, J.B. (2009). 'Safety climate: leading or lagging indicator of safety outcomes? Journal of Loss Prevention in the Process Industries, 22:735-739.

Privacy Rights Clearinghouse (2016). How to put an end to unwanted or harassing phone calls. Available at: https://privacyrights.org/consumer-guides/how-put-end-unwanted-or-harassingphone-calls, accessed 1 May 2020.

Rahman, M.M., Sykiotis, G.P., Nishimura, M., Bodmer, R., Bohmann, D. (2013). 'Declining signal dependence of Nrf2-MafS-regulated gene expression correlates with aging phenotypes'. Aging Cell 12(4): 554--562.

Reason, J., Manstead, A., Strading, S., Baxter, J., Campbell, K. (1990). 'Errors and violations on the roads: a real distinction? Ergonomics, 33(10-11):1315-1332.

Reddy, L.A., Espelage, D.L., Anderman, E.M., Kanrich, J.B., McMahon, S.D. (2018). "Addressing violence against educators through measurement and research". Agrresion and Violent Behaviour, 42 (2018), pp. 9-28.

Rodriguez-Repiso, L., Setchi, R., \& Salmeron, J. (2007). Modelling IT projects success with Fuzzy Cognitive Maps. Expert Systems with Applications, 32, 543-559.

Sa, J., Seo, D.C., and Choi, S.D. (2009). 'Comparison of risk factors for falls from height between commercial and residential roofers. Journal of Safety Research, 40(1):1-6. 
Schablon, A., Wendeler, D., Kozak, A., Nienhaus, A. and Stienke, S. (2018). "Prevalence and consequences of aggression and violence towards Nursing and Care Staff in Germany- A survey". International Journal of Environmental Research and Public Health, 15 (2018), pp. 1274.

Schoenfisch, A.L. and Pompeii, L.A. (2016). "Security personnel practices and policies in U.S. hospitals". Workplace Health and Safety, 64 (11), pp. 531-542.

Shamsuddin, K.A., Ani, M.N.C., Ismail, A.K. and Ibrahim, M.R. (2015). "Investigating the safety, health and environment protection in construction area". International Research Journal of Engineering and Technology, 2 (6), pp. 624-636.

Seddig, D. and Davidov, E. (20180. "Values, attitudes toward interpersonal violence, and interpersonal violent behaviour", Frontiers in Psychology, 9, 604.

Shen, Y., Ju C., Koh, T.Y., Rawlinson S. and Brige A. J., (2017). 'The Impact of Transformational Leadership on Safety Climate and Individual Safety Behaviour on Construction Sites'. International Journal of Environmental Research and Public Health, 14(45), pp. 1-17.

Silliker, A. (2015). "Objects falling from heights on construction sites lead to injuries". Available http:thesafetymag.com, accessed 19 March 2020.

Snook, J. (2015). Preventing bullying in the construction industry. Available at: https://gocontractor.com/blog/why-bullying-in-construction-is-a-problem/, accessed 1 May 2020.

Sohn, B.K., Park, S.M., Park, I-J., Hwang, J.Y., Choi, J-S., Lee, J-Y. and Jung, H-E. (2018). “The relationship between emotional labour and job stress among hospital workers". Journal of Korean Medical Science, 33 (39), pp. e246.

Sterman JD. (2000) Business Dynamics - Systems Thinking and Modeling for a Complex World. Irwin McGraw-Hill: Boston, MA.

Straub, D., Boudreau, M. C. and Gefen, D. (2004). 'Validation guidelines for IS positivist research'. The Communications of the Association for Information Systems, 13(1), p. 63.

Suraji, A., Duff., A.R. and Peckitt, S.J. (2001). 'Development of causal model of construction accident causation'. Journal of Construction Engineering Management, 127(4): 337-344.

Tepper, B. J. (2000). 'Consequences of abusive supervision'. Academy of Management Journal, $43,178-190$.

Tiesman, H., Konda, S., Hendricks, S., Mercer, D. and Amandus, H. (2013). "Workplace violence among Pennsylvania education workers: Differences among occupations". Journal of Safety Research, 44 (2013), pp. 65-71. 
Tong, R., Yang, Y., Ma, X., Zhang, Y., Li, S. and Yang, H. (2019). "Risk assessment of miners' unsafe behaviours: A case study of gas explosion accidents in coal mine, China". International Journal of Environmental Research and Public Health, 16(2019), pp. 1-18.

Tsui, C.W., Tzeng, G.H. and Wen, U.P. (2015), "A hybrid MCDM approach for improving the performance of green suppliers in the TFT-LCD industry", International Journal of Production Research, Vol. 53 No. 21, pp. 6436-6454.

Urbach, N. and Ahlemann, F., (2010). 'Structural equation modeling in information systems research using partial least squares'. Journal of Information technology theory and application, 11(2), pp.5-40.

Van Soest, D. and Bryant, S. (1995). 'Violence reconceptualized for social work: The urban dilemma'. Social Work, 40 (4), 549-557.

Walsh, B. R., and Clarke, E. (2003). 'Post-trauma symptoms in health workers following physical and verbal aggression'. Work and Stress, 17, 170-181.

Weiss, H. M., and Cropanzano, R. (1996). 'Affective events theory: A theoretical discussion of the structure, causes and consequences of affective experiences at work. In B. M. Staw and L. L. Cummings (Eds.), Research in Organizational Behaviour (Vol. 19, pp. 1-74). Greenwich, CT: JAI Press.

Wang, X., Katz, R. Schneider, S., Memarian, B. and Dong, X.S. (2017). "Struck-by injuries and prevention in the construction industry". CPWR Quarterly Data Report. Available https://www.cpwr.com, accessed 19 March 2020.

Williams, T.O., Billingsley, B. and Banks, A. (2018). "Incidences on student-on-teacher threats and attacks: A comparison of special and general education teachers". Journal of Special Education Leadership, 31 (1), pp. 39-49.

Williams, J., Fugar, F. and Adinyira, E. (2019a), "Assessment of health and safety culture maturity in the construction industry in developing economies: A case of Ghanaian construction industry", Journal of Engineering, Design and Technology, Vol. ahead-of-print No. ahead-of-print. https://doi.org/10.1108/JEDT-06-2019-0151

Williams J., Fugar F. and Adinyira E. (2019b) "Health and Safety Improvement Amongst Ghanaian Communities as a Corporate Social Responsibility of Construction Companies". American Journal of Construction and Building Materials. Vol. 3, No. 2, 2019, pp. 23-29. doi: 10.11648/j.ajcbm.20190302.11

Winnett, N. (2014). Construction Executive. [Online] Available at: http://enewsletters.constructionexec.com/riskmanagement/2014/10/workplace-violenceevaluate-and reduce-the-risk/ [Accessed 3 March 2017]. 
Wofgang, M. and Ferracuti, F. (1967). “The subculture of violence: Towards an integrated theory of criminology". London: Tavistock Publications.

Xu, S., Ni, Q.Q., Zhang, M. and Li, M. (2019). A personalized safety training system for construction workers. International Conference on Smart Infrastructure and Construction, Available https://doi.org/10.1680/icsic.64669.321.

Xu, S., Zou, P.X.W. and Luo, H. (2018). "Impact of attitudinal ambivalence on safety behaviour in construction". Advances in Civil Engineering, 2018, pp. 1-12.

Yenealem, D.G., Woldegebriel, M.K., Olana, A.T. and Mekonnen, T.H. (2019). "Violence at work: determinants and prevalence among health care workers, northwest Ethiopia: An institutional based cross-sectional study". Annals of Occupational and Environmental Medicine, 31(8), pp. 1-7.

Zerguine, H., Jalaludin, J., Tamrin, S.B.M. (2016). 'Behaviour based safety approach and factors affecting unsafe behaviour in construction sector: A review'. Asia Pacific Environmental and Occupational Health Journal, 2(2): 1-12. 